
BEZERROS DA RAÇA HOLANDESA

\author{
Andrei Kimura Mareandes de Castro
}

Dissertação apresentada à Faculdade de Zootecnia e Engenharia de Alimentos da Universidade de São Paulo, como parte dos requisitos para obtenção de Título de Mestre em Zootecnia - Área de Concentração: Qualidade e Produtividade Animal

Orientador: Prof. Dr. Marcus Antonio Zanetti 


\section{ESTUDO DA INCLUSÃO DE FIBRA NA DIETA DE BEZERROS DA RAÇA HOLANDESA}

Andrei Kimura Mareondes de Castro

Dissertação apresentada à Faculdade de

Zootecnia e Engenharia de Alimentos da

Universidade de São Paulo, como parte dos requisitos para obtenção de Título de Mestre em Zootecnia - Área de Concentração: Qualidade e Produtividade Animal

Orientador: Prof. Dr. Marcus Antonio Zanetti

DEDALUS - Acervo - FZEA

427

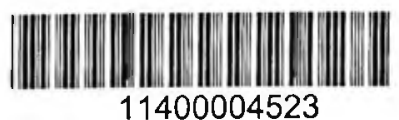

PIRASSUNUNGA

1996

BERVIÇO DE BIBLLO ECA E DOCUMENTAÇAO

Faculdade de Zootocnis. Engonharle do Allmantos

Univereldade de 810 Paule 


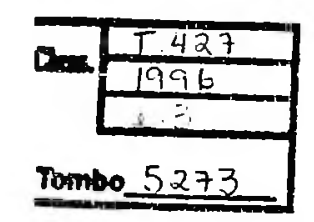

Preparada pela Biblioteca da

Faculdade de Zootecnia e Engenharia de Alimentos da Universidade de São Paulo

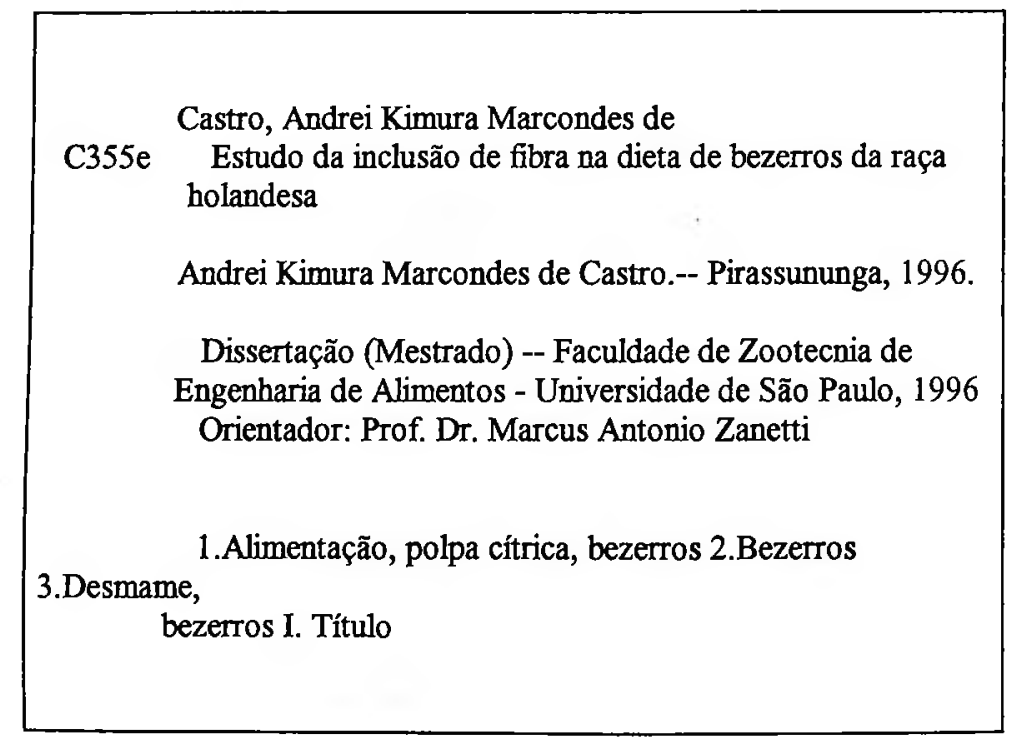


Dedicatória

A todos os pós-graduandos da FZEA e da FMVZ que estiveram presentes

neste momento,

à minha mãe, por ter me dado a luz,

à Tânia, minha namorada, por ter me dado amor,

e a Deus, por ter me dado a vida.

GERVICO DE GIBLIO EOCA E DOCUMENTAÇAC

Faculdado do Zootecnie Engonherla de Alimentoe

Unlveraldade de Seo Paule 


\section{Agradecimentos}

Ao Prof. Dr. Marcus Antonio Zanetti, pela orientação e dedicação,

À FAPESP, pelo auxílio financeiro,

À FZEA/USP, pela oportunidade de realizar este trabalho,

À Prefeitura do Campus Administrativo de Pirassununga da USP, pelo

apoio de infra-estrutura,

e a todos que contribuiram diretamente ou indiretamente para a realização

deste trabalho. 
SUMÁRIO

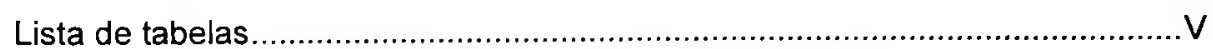

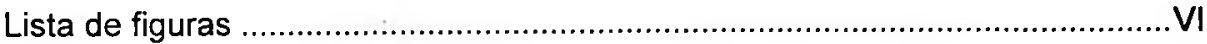

Lista de abreviaturas e siglas ...................................................... VII

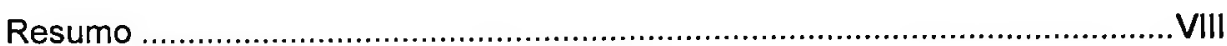

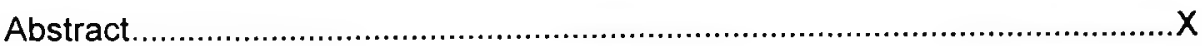

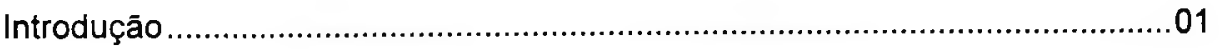

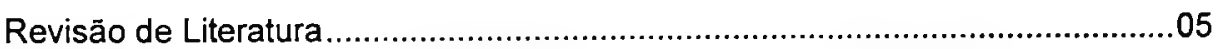

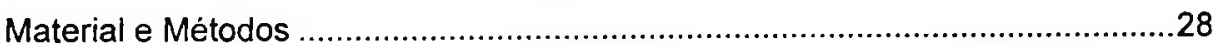

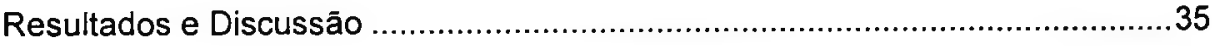

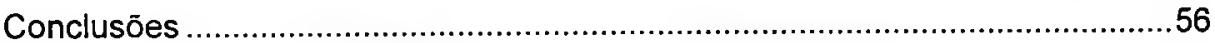

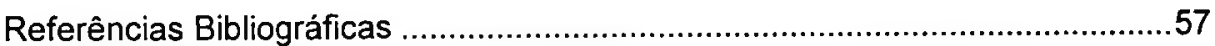




\section{LISTA DE TABELAS}

Tabela 01 - Composição percentual das rações experimentais (com base na matéria seca)

Tabela 02 - Composição bromatológica das rações iniciais em base seca

Tabela 03 - Composição bromatológica do feno de coast-cross e polpa citrica desidratada com base na matéria seca

Tabela 04 - Médias e coeficientes de variação dos ganhos de peso, ganho em altura total, conversão alimentar e consumo de MS diário, consumo de MS total por quilograma de peso vivo e quilograma de peso vivo metabólico.

Tabela 05 - Ingestão total de nutrientes $(\mathrm{kg})$ em base seca e seus respectivos coeficientes de variação

Tabela 06 - Médias diárias de consumo de alimentos sólidos $(\mathrm{kg})$ na matéria original e seus respectivos coeficientes de variação ao final do experimento

Tabela 07 -Médias do percentual volumétrico do R-R (rúmen-reticulo), O-

A (omaso-abomaso), $\mathrm{pH}$, altura das papilas tomadas com paquimetro e seus respectivos coeficientes de variação. 


\section{LISTA DE FIGURAS}

Figura 01 - Médias de ganhos de pesos diários $(\mathrm{kg})$ por tratamento corrigidos para peso inicial

Figura 02 - Consumo de matéria total $(\mathrm{kg})$, consumo de matéria seca por $\mathrm{kg}$ de peso vivo médio e consumo de matéria seca por kg de peso metabólico médio

Figura 03 - Ingestão total de nutrientes $(\mathrm{kg})$ - proteina bruta, fibra bruta, fibra em detergente neutro, fibra em detergente ácido e extrato etéreo

Figura 04 - Ingestāo total de nutrientes $(\mathrm{kg})$ - nutrientes digestiveis totais e extrativos nāo nitrogenados 44

Figura 05 - Ingestão total de matéria seca em quilogramas - feno e concentrado.

Figura 06 - Proporções volumétricas relativas dos conteúdos rúmenreticulo e omaso-abomaso

Figura 07 - Altura das papilas (mm) da parede do rúmen - saco ventral 51

Figura 08 - pH do conteúdo ruminal . 52 


\section{LISTA DE ABREVIATURAS E SIGLAS}

Ca - cálcio

PV - peso vivo

C.calcitico - calcário calcítico

PV $\mathbf{0}^{0,75}$ - peso metabólico

EE - extrato etéreo

$\mathbf{R}-\mathbf{R}$ - retículo e rủmen

EM - energia metabolizável

Trat. - tratamento

ENN - extrativos nāo nitrogenados

vit. - vitaminico

F. soja $46 \%$ - farelo de soja com $46 \%$ de proteína bruta

F.trigo - farelo de trigo

Vol. - volume

FB - fibra bruta

F.Bicálcico - fosfato bicálcico

FDA - fibra em detergente ácido

FDN - fibra em detergente neutro

GPDs - Ganhos de peso diários

Ing. - ingestāo

kg - quilogramas

MS - matéria seca

MM - matéria mineral

NDT - nutrientes digestiveis totais

O-A - omaso e abomaso

pH - potencial hidrogeniônico

P - fósforo

PB - proteina bruta 


\section{RESUMO}

CASTRO, A.K.M.de, Estudo de formas de inclusão de fibra na dieta de bezerros. Pirassununga, 1996. 67p. Dissertação (Mestrado) - Faculdade de Zootecnia e Engenharia de Alimentos, Universidade de São Paulo.

O trabalho foi conduzido na Faculdade de Zootecnia e Engenharia de Alimentos - USP e detalha o estudo de diferentes formas de inclusão de fibra na dieta de 24 bezerros da raça holandesa (PC). Foram estudados os seguintes tratamentos: a) leite + ração Inicial; b) leite + ração inicial com fibra incorporada utilizando-se de polpa cítrica desidratada e farelo de trigo, c) leite + ração inicial com $20 \%$ de feno de gramínea (Coast-cross, Cynodon dactilon) triturado e incorporado e d) leite + ração inicial + feno de gramínea triturado (Coast-cross, Cynodon dactilon) oferecido em separado, ad libitum. Cada uma das dietas foi oferecida a 6 (seis) bezerros, do nascimento até dois (2) meses de idade, em delineamento inteiramente casualisado, com pesagens semanais, controle de consumo de alimentos diário e abate ao término do período. Em seguida, procedeu-se à avaliação do desenvolvimento ruminal com base no volume dos pré-estômagos, no desenvolvimento das papilas ruminais e na análise do conteúdo ruminal (contagem de protozoários e determinação de pH). Diferiram significativamente $(p<0,05)$ : ganho de peso diário, consumo de matéria seca, consumo de matéria seca por quilograma de peso vivo, consumo de matéria seca por quilograma de peso vivo metabólico, ingestão de proteína bruta, 
nutrientes digestiveis totais, fibra bruta, fibra em detergente ácido, fibra em detergente neutro, matéria mineral e extrativos não nitrogenados. Concluiu-se que a utilização de polpa cítrica, para as condiçōes do experimento, como fonte de fibra incorporada na ração propiciou resultados semelhantes à dieta sem fibra extra e ambos inferiores as dietas com fibra proveniente de graminea. Sendo o melhor resultado observado para a dieta com feno incorporado à ração inicial.

Palavras-Chave: 1.Alimentação, polpa citrica, bezerros 2.Bezerros

\section{Desmame}




\begin{abstract}
In this research, were studied fiber inclusion in the diet of 24 holstein male calves, under the following treatments: a: milk + starter ration without fiber source, b: milk + calf starter with dehydrated citric pulp and wheat bran; c: milk + starter with $20 \%$ chopped coastal bermuda grass hay and d: milk + calf starter and coastal bermuda grass hay feed separately ad libitum. For each treatment was used six calves from calving until 2 months age. There was significant difference for daily gain, dry mater intake, dry mater intake/kg live Weight. dry mater intake/ $\mathrm{kg}$ metabolic weight, crude protein intake, total digestible nutrients intake, crude fiber intake, ADF intake, NDF intake, ash intake and non nitrogenous extract intake. It was concluded that, for the experimental conditions, the utilization of incorporated citrus pulp as source of fiber in the ration had the same results as the diet without extra fiber and both were inferior than the diets with grass fiber. The diet with calf starter with hay included presented the best results.
\end{abstract}

Keywords: 1.Alimentation, citrus pulp, calves 2.calves 3.weaning, calves

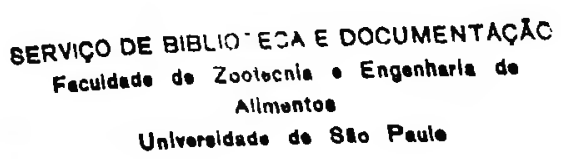




\section{INTRODUÇÃO}

Os sistemas de desaleitamento precoce de bovinos leiteiros são recomendados para fêmeas destinadas à reposição do rebanho, e aos machos destinados ao corte; embora nada impeça que estes sejam posteriormente utilizados como reprodutores.

A idade de desaleitamento do bezerro depende, basicamente, de dois fatores principais: o custo do aleitamento e o estado físico geral do bezerro. O custo do aleitamento foi, certamente, a principal causa do desaleitamento precoce; pois, quanto mais cedo for desaleitado o bezerro, mais leite poderá ser comercializado, resultando em maior rentabilidade para o produtor. Por outro lado, pode ocorrer que o bezerro não tenha desenvolvido completamente seu aparelho digestivo para o aproveitamento de concentrados e volumosos, como também, não apresentar um perfeito estado físico para sofrer essas modificaçōes. De certo, quando a funçāo ruminal apresenta-se adequadamente desenvolvida, os produtos da digestão e sintese ruminal podem ser considerados como um substituto natural do leite. Naturalmente, o estado do bezerro vai depender da quantidade de leite, de concentrado e de feno fornecidos durante a fase de aleitamento, quantidades estas que também dependem do custo destes alimentos. Assim, muitas vezes, o lucro obtido com o leite que deixou de ser fornecido ao bezerro traduz-se em prejuizo durante a fase produtiva do animal assim criado.

Para que a situação descrita nāo ocorra, os animais deverão apresentar-se saudáveis, mas enxutos, com pelame mais grosseiro do que o 
normal, poderão mostrar-se um tanto descarnados, mas entre 18 e 24 meses de idade, não deverá ocorrer distinção entre um animal criado em sistemas de desaleitamento precoce e um outro aleitado liberalmente. Para que isso aconteça, durante os 3 primeiros meses de vida, os ganhos de peso deverão ser iguais ou superiores a taxa de $0,875 \%$ do peso vivo. Este limite garante um bom crescimento do tecido ósseo, ainda que com um desenvolvimento acentuadamente inferior do tecido adiposo e com crescimento do tecido muscular mais modesto que nos sistemas liberais de aleitamento. $O$ importante foi que o tecido ósseo não seja comprometido, pois, assim, os ganhos de peso nos primeiros 3 meses de vida não afetariam o tamanho final do bovino.

A economia na alimentação dos ruminantes foi baseada fundamentalmente no pleno estabelecimento da função ruminal, com ênfase particular na digestão de volumosos e na síntese de proteinas de alta qualidade. No esforço de aplicar este axioma da alimentação de bezerros, trabalhos preliminares indicaram que 0 rúmen pleno de suas funçōes pode ser estabelecido em bezerros jovens mais cedo do que se pensava ser viável. O funcionamento da goteira esofagiana encoraja o fato de que: o uso de um regime líquido de alimentação necessita que o bezerro seja alimentado como um monogástrico, mas que $\circ$ uso de alimentos sólidos e uma indução à atividade ruminal poderá liberar o bezerro de suas limitaçōes iniciais características. Estas limitaçōes estão em sua inabilidade em utilizar sacarose, maltose, amido ou dextrina durante as suas 6 primeiras semanas de vida, e sua inabilidade de fazer uso satisfatório de proteinas 
vegetais 26 a 30 dias de idade, de maneira que na indução ao aproveitamento de material sólido, e para efetuar o desaleitamento precoce sem problemas, são indispensáveis um concentrado e um volumoso de boa qualidade, incluidos na dieta do bezerro de modo gradativo.

Um ponto a ser considerado foi o baixo consumo do feno e, neste particular, sua incorporação ao concentrado pode auxiliar. Há necessidade de ingestāo de fibras para o desenvolvimento saudável da mucosa do epitélio da parede do rúmen e para indução ao desenvolvimento do período de ruminação. Fato imprescindível para a colonização microbiológica adequada, alcançada através de um pH favorável e para desenvolvimento dos pré-estômagos (aumento da capacidade dos órgãos e reforço da musculatura), transformando o animal o mais prontamente possivel em ruminante. De fato, existem evidências indicativas de que torna-se dificil de manter a saúde em ruminantes jovens sem a adequada presença de volumoso na ração.

Há de se convir que, nas condiçōes brasileiras, as propriedades em sua maioria estão despreparadas para uma produção de feno de boa qualidade, ou onerarem-se na aquisição deste. Uma alternativa seria a utilização de capineiras de Napier, fornecendo capim picado aos bezerros. Entretanto, devido à sazonalidade da produção, esta técnica seria prejudicada durante o inverno, além de produzir uma grande variação na qualidade do capim com o passar do tempo. Estas dificuldades, aliadas ao baixo consumo de volumosos pelos bezerros, podem ser minimizadas com a incorporação de fibra no concentrado. Neste sentido, pode-se adotar uma 
fonte de fibra considerada de alta qualidade, por seu caráter de extrema solubilidade e degradabilidade no rúmen funcional, como a polpa citrica; ou uma fonte que apresente uma boa composição protéica, como a folha da alfafa. Esta última, no entanto, não isenta o produtor dos custos e do manejo inerentes à sua obtenção ou à compra de um produto diferenciado e, por esse motivo, caro. Está sendo proposta, no presente trabalho, uma alternativa que seria a de efetuar o desaleitamento precoce com utilização de fibra (na forma de polpa cítrica) incorporada à ração de desaleitamento.

Além do exposto, outras justificativa para a utilização da polpa cítrica no arraçoamento de animais são: a crescente disponibilidade deste produto no mercado interno, imposta pelas recentes condiçōes política e econômica do mercado externo; e o fato da polpa cítrica ter seu auge de produção extremamente favorável, com a safra iniciando-se em maio e terminando em janeiro, na entressafra de grãos e época de escassez de forragens.

Este trabalho teve como objetivos: o estudo dos efeitos da administração de feno isolado ou incorporado ao concentrado de bezerros até o desaleitamento, e a possibilidade da substituição do feno pela inclusão da fibra proveniente da polpa citrica, na ração de desaleitamento de bezerros. 


\section{REVISÃO de LITERATURA}

O ganho de peso vai depender de vários fatores e traduz-se no desempenho do animal, ROY (1980) e MARTIN et. al(1962) colocaram que o importante foi que o tecido ósseo não seja comprometido, pois assim, os ganhos de peso nos primeiros 3 meses de vida não afetariam o tamanho final do bovino. MARTIN et. al(1962) colocaram que o custo unitário do ganho de peso antes do desenvolvimento das funções ruminais foi maior do que aquele que ocorreu depois. Assim, parece ser mais recomendável manter os bezerros saudáveis durante os primeiros períodos de vida, sem grandes preocupações com altos índices de ganho de peso; mesmo porque deve-se ter em mente que existe pouca relação destes com a produção final de leite do animal.

O trabalho de UGARTE et. al(1972), mostrou uma maior eficiência da utilização do leite pelos animais que receberam $8,1 \mathrm{~kg}$ do que nos que ingeriram $5,4 \mathrm{~kg}$ por dia. No primeiro $7,7 \mathrm{~kg}$ de leite proporcionou $1 \mathrm{~kg}$ de ganho de peso e, no segundo, para cada $\mathrm{kg}$ de ganho de peso $8,6 \mathrm{~kg}$ de leite foram necessários, atestando que o leite foi o melhor alimento a ser fornecido aos neonatos.

BUSH \& NICHOLSON (1986) demonstraram que os bezerros, alimentados exclusivamente com leite à vontade, consumiram $250 \mathrm{~g} / \mathrm{kg}$ de peso vivo/dia, próximo à idade de desaleitamento. No entanto, quando a quantidade de leite foi restrita a $10 \%$ do $P V$, não houve diferença significativa no consumo de matéria seca. 
O consumo de alimentos foi um dos pontos de maior importância para que 0 animal tenha condições de se desenvolver adequadamente, HUBER (1977) recomendou o consumo de aproximadamente $750 \mathrm{~g} / \mathrm{dia}$ de concentrado para que o bezerro pudesse se sustentar. Segundo o mesmo, quase todos os bezerros estarão consumindo concentrado $\circ$ bastante para desmamar na sexta $\left(6^{a^{a}}\right)$ semana de idade e $70 \%$ na quarta $\left(4^{a}\right)$ semana continuar a alimentando-os com leite depois que estão prontos para desmamar não os ajuda, porque o desenvolvimento adequado do rúmen foi atrasado e foi antieconômico para o fazendeiro.

No experimento de WARNER et. al (1956), os bezerros que receberam leite mais ração inicial apresentaram, às 13 semanas de idade, pesos superiores àqueles que receberam feno, ou somente leite até 0 desaleitamento. No entanto aqueles animais que permaneceram na dieta só de leite, até a décima sexta $\left(16^{\mathrm{a}}\right)$ semana de idade tiveram maiores ganhos de peso. Os autores descontaram o conteúdo ruminal para obter o ganho de peso e minimizar a variação atribuída ao enchimento proporcionado pela dieta.

KERTZ et. al (1979) em extenso trabalho de revisão de experimentos ocorridos no EUA, verificaram que a média de consumo de concentrado por bezerro (em 25 experimentos, utilizando 277 animais), nos primeiros 45 dias de idade, foi de 288 gramas por dia; $12,96 \mathrm{~kg} /$ bezerro. $O$ consumo de ração inicial com o nivel de $5 \%$ a $7 \%$ de fibra, sem a inclusão de feno, foi responsável por $65 \%$ da variação total do ganho de peso.

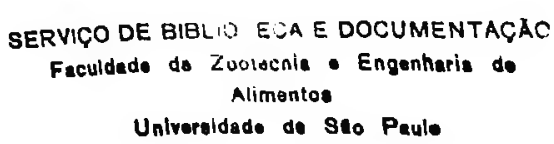


HIBS et. al (1953) verificaram que ao se aumentar a proporção do concentrado em relação ao feno, ocorreu aumento no ganho de peso. Todavia, este aumento pode ser questionado do ponto de vista econômico, especialmente se for considerado que, após o desaleitamento, os pesos tendem a se aproximar. No mesmo experimento, os autores verificaram que não houve diferenças de performance entre bezerros alimentados com leite até as 7 ou 9 semanas de idade. Exceto que os bezerros aleitados até 9 semanas de idade obtiveram maior custo médio por ganho de peso, e alguma supressão no consumo de alimento após as 6 semanas de idade. Estas diferenças no custo são atribuídas principalmente ao maior consumo de leite. Na prática, afirmaram os autores, o leite não deve ser retirado da alimentação se o bezerro não estiver ingerindo quantidades adequadas de alimento sólido. De fato, a ausência de queda na curva de crescimento, resultante da remoção do leite da alimentação, foi também uma evidência de um desenvolvimento adequado do rúmen durante o período de aleitamento.

KERTZ et. al (1979) observaram que muitos dos estudos publicados sobre bezerros, leite ou substitutos do leite são fornecidos exclusivamente. Em outros estudos, há ênfase nas raçōes iniciais com pouca ou nenhuma descrição do leite ou seu substituto. Ainda, segundo os autores, em condiçōes práticas, normalmente tanto o leite quanto seus substitutos e uma ração inicial são fornecidas, a interação destes dois componentes dietários necessitam de consideração, especialmente uma vez que o substituto de leite foi digerido no abomaso enquanto a ração inicial foi digerida 
principalmente no rúmen. Os autores citam que em bezerros não desmamados, foi possivel que o balanço de amino-ácidos resultante da "porção não ruminal da dieta" (leite ou substitutos deste) possam afetar o consumo da "porção da dieta ruminal" (ração inicial), para a qual os bezerros em estudo tiveram acesso.

THOMAS \& HINKS (1982), estudando a forma física dos volumosos, verificaram que os bezerros alimentados apenas com leite e concentrado (basal) obtiveram os menores ganhos de peso, corrigidos para pesos iniciais. Quando o concentrado foi tamponado (35g de bicarbonato de sódio/kg de alimento), o desempenho melhorou mas os ganhos mais altos foram obtidos com dieta basal, com a incorporação de $180 \mathrm{~g}$ de feno $/ \mathrm{kg}$ de concentrado. $O$ resultado deste tratamento foi superior ao obtido com o uso de feno inteiro e ao feno triturado, ambos oferecidos separadamente. Neste experimento os niveis de fibra bruta $5,87 \% 10,75 \%$ e os de Proteina Bruta foram $17 \%$ e $14 \%$, respectivamente para os tratamentos testemunha, e com $180 \mathrm{~g}$ de feno $/ \mathrm{kg}$ de concentrado.

A presença da fibra tem se mostrado importante em programas de alimentação de jovens pre-ruminantes. STOBO et. al (1966), em experimento com bezerros até os 3 meses de idade, observaram que a proporção de ingestão de feno em relação à ingestão de concentrado aumentou, à medida que se restringiu 0 acesso dos bezerros ao concentrado. Os autores afirmaram que o conteúdo do trato alimentar foi importante na avaliação de raçōes com diferentes niveis de fibra, desce que os animais alimentados com maiores quantidades de concentrado 
ganharam mais peso. Enquanto que, naqueles bezerros em que houve maior restrição ao concentrado, a proporção do ganho de peso vivo (atribuivel ao aumento no conteúdo do trato alimentar) foi maior. Atribui-se este aumento de conteúdo do trato ao maior consumo de feno decorrente da restriçāo ao concentrado. Conforme STROZINSKI \& CHANDLER (1971) tal medida, sem a dedução para o conteúdo do rúmen, não representou o ganho de peso real da carcaça.

NOLLER et. al (1962) ao fornecer feno triturado junto com o concentrado não encontraram diferenças no ganho de peso às 10 semanas de idade; considerando-se o feno oferecido isolado ou incorporado ao concentrado. Concluiu-se que o feno, apesar de poder ser utilizado, não precisou, necessariamente, ser consumido; e que, ao se fornecer feno "ad libitum", alguns animais consumiram muito pouco, tendo como conseqüência um menor desenvolvimento ruminal.

MACLEOD et. al (1969) obteveram resultados demonstrativos de que a inclusão $20 \%$ de feno de leguminosa, na ração inicial de bezerros, aumentou o consumo de concentrado, sem diferença significativa para as taxas de crescimento.

BUSH (1990) afirmou que os bezerros jovens não consumiram forragens numa proporção significante de sua dieta, quando seu acesso ao concentrado não foi restrito. Quando o concentrado foi restrito, no entanto, a matéria seca da forragem tornou-se uma proporção maior do total consumido, confome o avanço da idade do animal. Os bezerros tiveram 
preferência por alimentos baseados em muitos fatores diferentes, entre os quais, sabor, $\mathrm{pH}$, forma física e grau de processamento.

HUBER (1977) concluiu que a alimentação de bezerros não pode ser baseada em volumosos como a principal fonte de nutrientes até os quatro meses de idade, sendo imprescindivel o fornecimento de concentrados.

MARSH (1974) observou que as perdas de enchimento do trato digestivo, em período de jejum de 24 hs, foi maior para bezerros alimentados com feno do que para os alimentados com concentrado. WILLIAMS et. al (1985) observaram que após a correção para o enchimento do trato digestivo os GPDs, 150), 200 e 250 gramas de feno de cevada incorporado em $1 \mathrm{~kg}$ de ração, foram respectivamente $6,6,1,2$ e 1,0 quilogramas maiores que o que ocorreu com a ração basal sem feno. LUCCl et. al(1976 b) demonstraram não haver evidência de que os conteúdos dos tratos digestivos em rações que continham $25 \%$ de feno incorporado, fossem maiores que em rações sem feno. No entanto, o mesmo trabalho demonstrou que foram maiores os pesos dos quatro ventrículos repletos, ou do rúmen-retículo repletos, bem como maiores pesos dos conteúdos do rúmen-retículo ou do total dos quatro ventrículos, para os tratamentos com feno incorporado; justamente aqueles que apresentaram maiores ganhos de perímetro abdominal: sugerindo uma relação entre essas variáveis.

JAHN et. al(1970), em experimento de diferentes niveis de fibra, ponderaram que o enchimento, como percentagem do peso vivo, aumentou linearmente $(p<0.01)$ com $\circ$ aumento de conteúdo fibroso na ração. Comprovaram que, inicialmente com os animais com uma idade de 8 
semanas, o peso relativo deste conteúdo dos ventrículos foi de $14 \%$ do peso vivo, e que ao final de 21 semanas de idade este mesmo peso relativo variou de 10 a vinte e quatro por cento $24 \%$ do peso vivo do animal. Utilizaram-se, então, de uma correção para medir a influência do grau de enchimento proporcional à fibra da ração, e obter o peso vivo corrigido. Tal procedimento revelou que o ganho de peso corrigido diminui com o aumento do nivel de fibra; indicando ainda que, com o aumento do nivel de fibra, proporção considerável do ganho de peso vivo foi devido ao aumento no conteúdo do trato alimentar. Quando rações de vários níveis de fibra estão sendo avaliadas com base no ganho de peso vivo, os resultados podem ter sido facilmente confundidos devido às diferenças entre os graus de enchimento dos tratos digestivos.

NOLLER et. al (1962), em experimento que apresentou niveis energéticos de $71,78 \%$ e $60,8 \%$ de NDT e $19,31 \%$ e $11,55 \%$ PB, respectivamente, concluiram que, quando se forneceu feno triturado junto com a ração inicial, ocorreu um aumento na ingestão de feno.

WILLIAMS et. al (1985) observaram que, com a adição do feno na dieta, o volume do rúmen aumentou duas vezes aos 42 dias e 7,11 vezes aos 87 dias. STOBO et. al (1966) registraram o aumento da capacidade volumétrica do retículo-rúmen, à medida que se restringia o fornecimento de concentrado com conseqüente aumento de consumo de feno fornecido "ad libitum". Este considerável aumento no tamanho do retículo-rúmen que ocorre quando alimento solido foi fornecido, foi acompanhado por um aumento relativamente pequeno na espessura a musculatura da parede, 
sugerindo que a musculatura do retículo-rúmen foi suficientemente desenvolvida para 0 inicio dos movimentos numa idade jovem como postulado por ROY(1956) apud STOBO et. al (1966) e BENZIE \& PHILIPSON(1957). Por outro lado, houve um considerável aumento na espessura relativa da mucosa, particularmente no retículo e nos sacos ventral e dorsal anterior do rúmen, mostrando que a maior parte do aumento do peso do tecido foi devido à espessura da mucosa.

LUCCl et. al (1976 b) utilizando-se de 6 bezerros recebendo raçōes iniciais sem feno incorporado e com $25 \%$ de feno incorporado até 91 dias de idade, sob controle semanal de peso vivo e controle diário de consumo de alimentos, verificou que não houve evidências de diferenças entre os tratamentos com relação ao desenvolvimento volumétrico dos ventrículos.

WILLIAMS (1985) et. al em experimento que utilizou vários niveis de inclusão de fibra na dieta verificaram que a inclusão de feno de cevada na dieta aumentou a ingestão de MS e fibra, não havendo efeito no consumo com o aumento da proporção de feno. Observou-se que dos 14 aos 56 dias de idade o consumo de concentrado aumentou pela adição de feno, mas foi negativamente correlacionado com a proporção deste na dieta.

Quanto ao teor de fibra bruta na dieta, THOMAS \& HINKS (1983) em experimento até os 9 meses de idade concluiram ser mais adequado para máximo ganho de peso o nível de $15 \%$ de FDA ( $220 \mathrm{~g}$ de feno moído) incorporado na ração, embora o consumo máximo de matéria seca ocorreram com $240 \mathrm{~g}$ de feno por quilograma de dieta. JAHN et. al (1970) obtiveram ingestão máxima para uma ração com $23 \%$ de fibra em 
detergente ácido (ADF) para animais entre 8 e vinte e três 23 semanas de idade. WILLIAMS et. al (1985) obtiveram melhores ganhos de peso com $116,6 \mathrm{gDA} / \mathrm{kg}$ MS, para animais com idade superior a 5 meses e ingestão de matéria seca, antes do desaleitamento 1,63 de vezes maior que a da dieta basal.

A palatabilidade tem sido responsabilizada por parte da variação nos experimentos com alimentação animal. Em trabalho de revisão, LUCCI (1989) afirmou que o consumo médio de feno, por bezerro holandês, até os 70 dias de idade, foi de vinte quilogramas $20 \mathrm{~kg}$. MARSH(1974) demonstrou que bezerros alimentados com feno, de média qualidade, tenderam a comer mais que os que tiveram a disposição feno de alta qualidade. Neste experimento, observou-se uma relação inversa entre o coeficiente de digestibilidade dos alimentos e o nivel quantitativo de arraçoamento. Confirmou-se, também, que os melhores ganhos de peso diário foram obtidos para o feno de média qualidade. $O$ autor ressalvou que a palatabilidade, a compactação do fardo e a presença de bolores, provavelmente, devem ter causado variaçōes no consumo.

Segundo HUBER (1977) a palatabilidade foi uma das caracteristicas mais importantes de um concentrado para bezerros. Para ser palatável, um concentrado precisa ter um sabor doce e uma textura não muito fina. Portanto, o grau de moagem não deve ser muito fino. Partículas finas só podem ser incluidas se forem peletizadas. Um sabor amargo certamente irá reduzir o consumo de concentrado pelos bezerros. 
HIBS et. al (1953) enfatizou a qualidade e aceitabilidade do volumoso em experimento, no qual a utilização de feno de alfafa resultou em maior crescimento e maior eficiência de utilização do alimento, do que o feno de trevo "timothy". KERTZ et. al (1979) demonstraram que $(0,11 \mathrm{~kg}$ de aumento no consumo de ração inicial resultou num aumento do ganho diário de $0,09 \mathrm{~kg}$ no peso, indicando a importância da palatabilidade no consumo de ração inicial.

Em experimento com controle de consumo voluntário de silagem de graminea, feno de alfafa e feno-silagem, BUSH (1990) verificou que o consumo de alfafa foi $21 \%$ maior que o de feno de gramínea, $8 \%$ maior do que o de silagem e $14 \%$ menor do que o de feno de alfafa:silagem com base em FDN. O mesmo autor justificou estes resultados pelas diferenças na proteina da forragem, e pela possivel associação da taxa de digestibilidade da parede celular com a quantidade desse material, especialmente se foram consideradas diferentes fontes de volumosos.

VAN SOEST (1982) afirmou que a taxa de digestão máxima foi determinada pelas caracteristicas do substrato e suas propriedades fisicoquímicas. A passagem da fibra através do rúmen denota remoção seletiva das porções mais lentamente digeridas do substrato através de escape do rúmen proporcionando à população microbiana maior dependência das porções mais rapidamente degradáveis. A relação taxa de digestão/taxa de passagem foi, portanto, um fator fundamental na determinação do balanço da população microbiana e sua eficiência, assim como no consumo de alimento. Bactérias livres não aderidas tenderam a serem lavadas pela taxa 
de passagem dos líquidos que, freqüentemente, foi mais rápida que a de partículas e, por sua vez, inversamente relacionada ao tamanho das partículas da fibra. Isso explicaria o efeito adverso de taxas de passagens rápidas, ocasionado pela moagem dos alimentos, sobre a digestão celulolítica. MURPHY \& KENNEDY (1993) colocaram que a geração e movimento das partículas da digesta nos ruminantes, foram reconhecidos como um importante componente em seu metabolismo e digestão. Enfatizaram, ainda, que o processo de redução de tamanho de particula foi fundamental no controle de ingestão, que para volumosos foi depressor à resistência para a passagem de particulas do reticulo-rúmen. Este efeito foi ilustrado pelo aumento do consumo de forragem resultante da redução do tamanho mediante a moagem necessária para a peletização. Entre as dietas, o nivel de consumo foi algumas vezes relacionado, positivamente, com a média do tamanho das partículas, mas existiu uma relação não tão simples entre a extensão da redução do tamanho das particulas da dieta e o conteúdo em fibra. Evidentemente, tanto o conteúdo em fibra quanto a estrutura tridimensional dos tecidos de sustentação foram importantes na determinação do padrão de fragmentação decorrentes da mastigação.

O desenvolvimento do aparelho digestivo propicia ao animal melhores condiçōes de aproveitamento do alimento, GODFREY (1961a) constatou que, em relação ao desenvolvimento dos pré-estomagos, o volume do abomaso teve, inicialmente, maior taxa de crescimento; e o seu peso dobrado, rapidamente, em uma semana. O reticulo-rúmen e o omaso dobraram, respectivamente, em duas (2) e três (3) semanas o seu peso em 
relaçāo ao do nascimento: Logo após a primeira (1a.)semana, a taxa de crescimento do abomaso decresceu vagarosamente, apesar de, após 8 semanas, ter seu peso aumentado em 3 vezes em relação àquele do nascimento. Neste estágio, o omaso aumentou seu peso 5 vezes. $O$ mais rápido crescimento em peso foi obtido pelo retículo-rúmen que, às oito 8 semanas, multiplicou-se 8 vezes seu peso. Foi clara uma relação inversa do desenvolvimento do abomaso e do retículo-rúmen. O mesmo se observou quando se considera o volume destes órgãos, como foi descrito no trabalho de WARNER et. al (1956). Relatam SISSON \& GROSSMAN (1938) que, ao nascimento, o retículo-rúmen constitui aproximadamente um terço da capacidade total dos estômagos; aumentando até aproximadamente $85 \%$ na maturidade.

O desenvolvimento do "estômago composto" e o estímulo ao metabolismo típico de ruminante foram estimulados por fatores físicos, bem como químicos. SANDER et. al (1959) em experimento realizado até 5 semanas de idade, com inoculação utilizando-se de butirato de sódio, propionato de sódio, acetato de sódio, cloreto de sódio ou glucose em fístula, afirmaram que o conteúdo em água no retículo-rúmen (volume) de bezerros que receberam butirato de sódio, foi decididamente maior que aqueles submetidos a outros tratamentos. $O$ autor não apresentou base fisiológica para este aumento no volume.

O fenômeno da ruminação foi, igualmente, de grande significação para o estabelecimento das funções fisológicas e metabólicas do rúmen,através do estimulo à formação do habitate adequado aos 
microrganismos simbióticos ao ruminante. BARTLEY (1976), apud MURPHY \& KENNEDY (1993), mencionou que a quantidade de saliva secretada varia, inversamente, com o conteúdo de água da dieta e, diretamente, com a quantidade de matéria seca consumida. Alimentos ingeridos rapidamente, como feno moido ou peletizado ou concentrado, induziram menor salivação que aqueles consumidos mais lentamente, e como se sabe a saliva foi importante para elevar o $\mathrm{pH}$ do rúmen.

Segundo WESTON et. al (1989), apud MURPHY \& KENNEDY (1993), a duração da ruminação aumentou com o consumo dietário e o conteúdo fibroso até um máximo de 12 hs por dia. SWANSON \& HARRIS JUNIOR (1958) relacionaram positivamente o tempo de ruminação com o consumo de matéria seca. $\mathrm{LUCCl}$ et. al(1980) verificaram que tratamentos com volumosos apresentaram tempos de ruminaçăo significativamente maiores $(p<0,01)$ do que os tratamentos sem volumosos. Verificou-se uma relação estreita e direta entre os tempos despendidos em ingerir alimentos e a quantidades de alimentos ingeridas, com uma correlação de 0,673 entre tempo de ingestão de concentrado e volumoso versus matéria seca total ingerida com probabilidade de $1 \%$, em média geral para diversas idades.

BUSH(1990) atribuiu à atividade ruminal uma relação direta com o manejo e a alimentação impostos ao bezerro.

O desenvolvimento de papilas ruminais foi função do tipo de dieta, da pronta colonização pelos microrganismos no rúmen e a produção de metabólitos que desencadeiam direta, ou indiretamente, o estímulo à atividade do epitélio ruminal. $O$ inicio da atividade do rúmen, segundo 
ANDRIGUETTO et. al (1984), ficaria na dependência do tipo de dieta que o bezerro estivesse recebendo. $O$ animal recém nascido apresentou mucosa do rúmen lisa. O desenvolvimento das papilas mostrou-se dependente de alguns produtos originários da digestão; com destaque aos ácidos graxos voláteis liberados da fermentação dos concentrados ingeridos e presentes no rúmen (no caso, o $\mathrm{AGV}$ mais importante foi o ácido butírico). $\mathrm{O}$ aumento do número de papilas no rúmen permitiu formar uma maior área de absorção, acelerando a passagem de maior quantidade de nutrientes para a corrente circulatória. Também foi importante a administração de alimentos volumosos (feno ou forragem fresca) para o desenvolvimento do rúmen. Estes alimentos, além de contribuirem para formação da microflora típica do rúmen, provocaram o aumento do $\mathrm{pH}$ no seu interior, fornecendo meio adequado para o desenvolvimento da microflora. Os volumosos ainda contribuiram para o aumento do volume do rúmen e para o fortalecimento do tecido muscular de suas paredes; elevando, conseqüentemente, o número de movimentos e a potência das contrações ruminais. Por outro lado, o fornecimento de alimentos volumosos contribuiu para impedir o aparecimento de paraqueratose, comum em bezerros que receberam apenas concentrados, além do leite. Os volumosos, atraves da ruminação, aumentaram, efetivamente a salivação - de grande importância para o aumento do $\mathrm{pH}$ ruminal.

LUCCl et. al(1976) em experimento em que se utilizaram dois niveis de energia ( 76,18 e $69,23 \%$ de NDT), concluiram que a ausência de feno de alfafa incorporado às rações iniciais de bezerros até os 91 dias de idade, 
com desaleitamento aos 56 dias de idade, não implicou em surgimento de problemas na mucosa do rúmen, como placas, sedimentações de detritos ou erosões. Porém foi fornecido feno de alfafa à vontade a partir do $13^{\circ}$ dia de vida paratodos os animais, em todos os tratamentos.

Segundo DZIUK (1988), o desenvolvimento das papilas não foi estimulado por ação mecânica dos materiais volumosos, introduzidos no rúmen de animais alimentados com leite. Entretanto, observou-se que os AGVs estimulam o crescimento papilar, quando colocados no rúmen. Possivelmente o efeito da estimulação dos AGVs resultou do metabolismo destes no epitélio do rúmen, principalmente os ácido butírico e propiônico.

SANDER et. al(1959), demonstraram que o aumento da atividade metabolica do epitélio ruminal em combinação com um maior fluxo de sangue (que possivelmente ocorreu devido a presença de butirato de sódio), pode contribuir para o desenvolvimento do mesmo. Os autores afirmaram que a proporção de desenvolvimento da mucosa deve estar relacionada com o grau de atividade fisiológica e bioquimica dos compostos que passam pela membrana do rúmen via absorção, metabolismo e aumento do fluxo de sangue. Os efeitos específicos do aumento do fluxo de sangue são dificeis de predizer; mas, certamente, pode-se esperar uma associação a um rápido crescimento tissular. Porquanto o crescimento papilar foi o resultado do metabolismo de certos compostos pela parede do rúmen, e/ou seu efeito no fluxo de sangue.

STOBO et. al (1966) observaram papilas com altura média $2,1 \mathrm{~mm}$ em animais alimentados exclusivamente com leite até as 3 semanas de 
idade. Estes autores determinaram altura de papilas na região da prega retículo-ruminal, nos sacos dorsal e ventral próximo aos pilares coronários. Eles elegeram as regiões do saco ventral do rúmen como local de colheita de tecido epitelial para mensuração de comprimento das papilas.

BROWNLEE (1956) também adotou, como local de colheita papilar, a parede ventral do saco anterior dorsal do rúmen; observando que rúmens, expostos à presença de material sólido, desenvolveram mais as papilas, bem como aqueles animais que tiveram acesso à uma ração mais concentrada, em relação àqueles que consumiram mais feno. $O$ autor alerta que verificada visualmente a diferença de desenvolvimento papilar e separada a membrana mucosa da capa muscular, esta foi mais pesada em relação ao peso do rúmen como um todo. O mesmo justifica, assim, a adoção do peso da membrana mucosa como um "index" do desenvolvimento papilar. Como as papilas variaram consideravelmente em tamanho, em diferentes áreas anatômicas do rúmen podendo, também, variar dentro de uma determinada área, fundamentando-se que o único modo preciso de se expressar o desenvolvimento papilar poderia ser em termos de peso.

FLATT et. al (1959) , afirmaram que os critérios mais sensiveis para medir o efeito das várias dietas sobre o desenvolvimento do rúmen são as medições das papilas da mucosa deste órgão e da sua capacidade de volume.

Com relação à produção de AGVs, foi de senso comum, como atestou MAYNARD et. al (1984), que os alimentos volumosos foram 
acetogênicos e butirogênicos, enquanto os concentrados foram, a principio, propionicogênicos. WILLIAMS et. al (1985) demonstraram que, com o aumento de fibra na dieta, $\mathrm{o}$ acetato aumentou, enquanto o propionato e $\circ$ valerato diminiram, havendo pouco efeito no butirato. VAN SOEST (1982) afirmou que existe uma tendência em pensar que a produção de ácido acético diminuiu, à medida que introduzimos maiores quantidades de concentrado na dieta de ruminantes; no entanto, deve-se levar em consideração a proporção molar de produção dos ácidos. Esta observação tem fundamentado trabalhos como o de THOMAS \& HINKS (1982), que obtiveram maiores ganhos de peso para rações onde houve presença de fibra em comparação com aqueles em que não houve, pelo simples fato de que a presença da fibra estimula a ingestão de outros nutrientes, aumentando a produção de AGVs, mesmo que a fibra por si só tenha o ácido acético como principal produto de sua fermentação.

DIJKSTRA (1994) relacionou a produção molar dos AGVs com as interaçōes existentes entre as composiçōes quimicas dos substratos, taxa de despolimerização dos substratos disponiveis, organismos e preferências e estratégias de fermentação destes; bem como pH e mudanças nos caminhos metabólicos, devido a estas interaçōes. BUSH (1986) lembrou que, em animais adultos, o tecido epitelial está envolvido em alguns processos fisiológicos, notadamente na transformação de ácido butírico em corpos cetônicos .Os AGVs também são absorvidos pelo tecido e, com exceção da porção metabolizada, aparecem na veia porta. No entanto, poucas informações estão disponiveis a respeito das mudanças

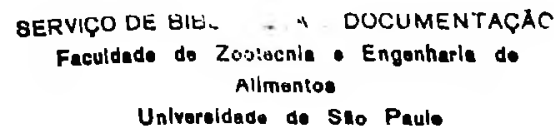


metabólicas, que ocorrem no epitélio durante o desenvolvimento dos ruminantes. Neste estudo, verificou-se que a habilidade de metabolizar os AGVs em corpos cetônicos desenvolveu-se gradativamente e dependeu da dieta ou, mais especificamente, dos AGVs usados como substrato e da presença de papilas. ANDERSON et. al (1987) reforçaram algumas das idéias acima por estarem de acordo que a ração inicial e o feno foram importantes no processo do desaleitamento precoce, propiciando o crescimento papilar e o aumento da capacidade ruminal.

A instalação de protozoários no rúmen é um parâmetro importante que atesta a trasnformação para ruminante, além de ser importante para o processo digestivo. COLEMAN, (1986) relacionou a presença de protozoários com a digestibilidade das fraçōes fibrosas. $\mathrm{O}$ autor determinou $65 \%$ a $85 \%$ de atividade celulolítica, imediatamente antes da refeição, associada à presença de protozoários, em ovelhas mantidas a base de feno e aveia.

YODER et. al (1966) encontraram "in vitro", que uma população mista de ciliados, livre de bactérias, digeria $6,9 \%$ da celulose em um determinado período, uma amostra de bactérias $39,7 \%$ e uma amostra de bactérias mais ciliados em proporções ótimas digeriam $60 \%$ da celulose.

ORPIN (1983/84), ORSKOV \& RYLE (1990), VALVASORI et. al (1992) obtiveram resultados que indicaram maior tolerância a meios ácidos por bactérias do que por protozoários. Os autores observaram ainda que o gênero Entodinium sp. resistiu a um meio mais ácido do que outros protozoários ciliados. 
LENGEMANN \& ALLEN (1955) em experimento que forneceu leite (aos bezerros até os seis -6- meses de idade), feno, e um concentrado com dezesseis (16\%) de proteína bruta não encontraram protozoários no rúmen á idade de 1 mês e encontraram protozoários $\left(137 \times 10^{3}\right.$ por $\left.\mathrm{ml}\right)$ em bezerros com a idade de 2 meses, associando a presença destes a um indicativo de início de transformação, em aparelho digestivo composto de um ruminante adulto. Os autores coletaram material ruminal sólido em quantidades suficientes para as análises; que, segundo os mesmos, foi um indicativo de que mesmo os animais mais jovens estavam ingerindo algum feno e grãos.

Há necessidade de se propiciar um $\mathrm{pH}$ adequado no rúmen para que os microganismos possam colonizá-lo, de forma que STROBEL \& RUSSEL (1986) sugeriram a interação entre o pH e o substrato, por estabelecerem uma correlação entre um aumento da proporção molar de ácidos butírico e de ácido lático; bem como uma diminuiçăo do ácido propiônico, quando o $\mathrm{pH}$ diminuiu de 6,7 a 5,8. Espécies de microoganismos diferentes podem ter causado essa variação. Variações nos substratos aumentaram as proporções molares de todos os três ácidos, quando o $\mathrm{pH}$ diminuiu.

A acidificação do rúmen não só desfavorece a microflora necessária, como também diminui, ou suprime, as contrações ruminais e a ingestão de alimentos; consubstanciando-se justamente, segundo ASH (1959), o consumo pronto de alimentos sólidos como a ação que garante o sucesso do desaleitamento precoce. 
Segundo NOGUEIRA FILHO (1981) $\circ \mathrm{pH}$ do rúmen de bezerros recém nascidos variou entre 2 e 2,5. Já GODFREY (1961b), mencionou um $\mathrm{pH}$ ruminal ao redor de 5 para bezerros recém nascidos. Há necessidade de maiores estudos sobre esta informação, contudo $\circ \mathrm{pH}$ precisa elevar-se, a fim de propiciar condiçōes para uma colonização adequada.

BUSH (1990) encontrou um pH crescente, à medida que aumentavase o consumo de forragem em relação ao concentrado. O mesmo observou que para os diversos tipos de volumosos utilizado em seu experimento, o pH às 8 semanas de idade esteve com a média em torno de 6,78 .

WILLIAMS et. al(1985) demonstraram que, com uma quantidade de feno de cevada crescente de zero (0) a $25 \%, 0 \mathrm{pH}$ do rúmen aumentou em torno de uma (1) unidade, concluindo que no fluido ruminal a elevação do $\mathrm{pH}$ foi o resultado do aumento de consumo de forragem. THOMAS \& HINKS (1982) observaram pHs maiores às 9 semanas de idade para dietas com feno incorporado, mencionando que houve maior necessidade de ingestão de feno, quando este foi moído para se obter valores de $\mathrm{pH}$ mais elevados.

VAN SOEST (1982) indicou que a digestibilidade da pectina foi alta e como seus produtos fermentativos AGVs e bactérias. FEGEROS et. al (1995) obtiveram $78,6,52,7,82.0,93,2$ e $83,1 \%$ de digestibilidade respectivamente para MS, Matéria Original, $\mathrm{PB}, \mathrm{EE}, \mathrm{FB}$ e ENN para a polpa cítrica seca em carneiros.

STROBEL \& RUSSEL (1986) em ensaio "in vitro", determinaram que a um $\mathrm{pH}$ inicial de 6,7 a fermentação de pectina fornece acetato, butirato e propionato em ordem decrescente de concentração. 
CARVALHO (1995) qualifica a pectina como fibra solúvel, enquanto VAN SOEST (1982) refere-se a ela como um polissacarideo rico em ácido galacturônico que ocorre na lamela média e outras membranas dos vegetais distinguindo-se da hemicelulose, porquanto esta outra foi uma fração mais complexa da estrutura da parede celular. As pectinas são mais abundantes em dicotiledôneas que em monocotiledôneas, em particular nas gramíneas e suas fontes comerciais provêm de maçãs e frutas cítricas. São dissolvidas por detergentes neutros e não são recuperadas com outros componentes da parede celular. No entanto, sua perda não foi considerada um problema grave, uma vez que ela apresenta essencialmente disponibilidade total.

Ao se referirem à polpa cítrica FEGEROS et. al (1995) e BENGHEDALIA et. al (1989) consideram-na um alimento concentrado energético, cujos componentes do grupo de carboidratos rapidamente fermentáveis são os residuos pécticos do ácido urônico e frutose. Porém, carrega caracteristicas, sob o aspecto de fermentação ruminal, que o qualificam como um produto intermediário entre volumosos e concentrados, apresentando alta digestibilidade da MS (superior ao amido de milho) e fermentação predominantemente acética.

BEN-GHEDALIA et. al (1989) observam que, enquartto a taxa de fermentação do amido foi de considerável variação dependendo da fonte, a pectina foi invariavelmente considerada como o complexo de carboidratos mais rapidamente fermenteciveis. Utilizando-se um tratamento que consistiu de polpa cítrica desidratada e farelo de soja em comparação com outro que consistiu de cevada e uma pequena porção de polpa citrica. Verificaram-se 
que seus valores de pHs foram, respectivamente, de 6,42 e 6,18; a relação acetato/propionato no rúmen foi mais alto para o primeiro tratamento. A polpa cítrica, quando em alta proporção na dieta, criou condições favoráveis para a atividade celulolítica no rúmen e teve um efeito positivo no suprimento de $\underline{\mathrm{N}}$ no intestino.

CARVALHO (1995) lembrou que, nos alimentos em geral, a parede celular, representada pela fração FDN, apresentou degradação lenta em comparação com o conteúdo celular. Deste modo, apresentou limitações ao fornecimento de energia em animais de alta exigência nutricional. Porém, o produto final da fermentação foi majoritariamente o ácido acético, que não reduziu o pH ruminal como o fazeram os ácidos propiônico e lático.

SCHAIBLY \& WING (1974) em experimento in situ, utilizando novilhas da raça Jersey, observaram que, apesar da maior relação acético/propiônico na substituição crescente de silagem de milho por polpa cítrica $(0,1 / 3,2 / 3$ e $3 / 3$ de substituição) em dieta de novilhos, $\mathrm{opH}$ ruminal foi reduzido, como se esperava no caso da substituição de volumosos por concentrados. Esta queda de $\mathrm{pH}$, no entanto, não foi drástica, como o que ocorreu para concentrados convencionais. Neste experimento, a digestibilidade de MS e energia aumentaram até o nivel de dois terços $(2 / 3)$ de substituição, a digestibilidade da proteína diminuiu apenas no tratamento, no qual houve substituição total. FARIA et. al(1972) caracterizou-a como alimento com alto teor de carboidratos solúveis, com resultados superiores à quarenta por cento $(40 \%)$ da MS no material fresco $13,5 \%$ de MS. 
BHATTACHARYA \& HARB (1973) colocaram que a polpa citrica foi de reduzido valor protéico, com perfil de amino-ácidos pobre, que, em se tratando de material que sofreu secagem, a fração nitrogenada apresenta retenção significante na FDA, com valores observados de $50 \%$ de proteína retida no FDA em amostras com sinais de formação de complexos de Maylard.

Segundo CARVALHO (1995) o fornecimento de polpa cítrica para bezerros até 60 dias de vida foi questionável por causa da palatabilidade para esta categoria. HARRIS JUNIOR \& STAPLES (1989) recomendaram até $10 \%$ da dieta para animais com idade de até 60 dias. 


\section{MATERIAIS E MÉTODOS}

O presente experimento foiconduzido na Faculdade de Zootecnia e Engenharia de Alimentos da Universidade de São Paulo no CAMPUS Administrativo de Pirassununga da Universidade de São Paulo, com inicio em novembro do ano de 1995.

Foram utilizados 24 bezerros da raça holandesa, machos, recémnascidos após terem ingerido colostro do nascimento aos 60 dias de idade. O fornecimento de colostro na fazenda de origem procedeu-se por 3 dias após o nascimento. Nas primeiras 12 horas após o nascimento os bezerros permaneciam com as mães, sendo fornecido colostro à vontade. Após 12 horas do nascimento, os bezerros permanesceram em baias individuais, sendo fornecido 4 litros de colostro diariamente, divididos em duas refeições iguais.

Os bezerros foram submetidos aos tratamentos que tiveram duração de 60 dias, ao final dos quais foram abatidos. A duração total do experimento foi de 3 meses, e dependeu dos bezerros disponiveis no momento da realização do trabalho, uma vez que foram adquiridos junto à uma fazenda da região.

Os animais receberamm $3 \mathrm{~kg}$ de leite integral de vaca, fresco, divididos em duas refeições diárias no primeiro mês, sendo que no segundo mês, foram fornecidos apenas $1,5 \mathrm{~kg}$ de leite por dia em uma refeição pela manhã, deixando no restante do dia apenas o alimento sólido. Considerando que o peso vivo médio no primeiro mês foi $38,4 \mathrm{~kg}$ e no segundo mês foi $49,8 \mathrm{~kg}$ foi fornecido $7,8 \%$ e $3 \%$ dos pesos vivos médios para o $1^{\circ}$ e $2^{\circ}$ mês,

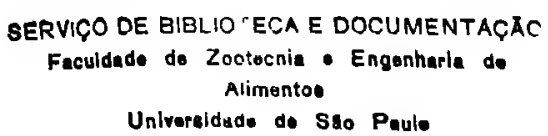


respectivamente, em leite. A composição do leite fresco foi adotada como $12 \%$ de MS; $26,7 \%$ de PB ; $0 \%$ de FB; $29,5 \%$ de EE; $6,3 \%$ de MM e $25,5 \%$ de ENN na matéria seca conforme o NRC(1988). Houve necessidade de redução das quantidades de leite fornecida aos bezerros pelo fato de alguns deles terem apresentado diarréia ao chegarem. Para padronização das quantidades de leite fornecido esta foi reduzida para todos os bezerros.

Os animais foram distribuídos aleatoriamente nos seguintes tratamentos:

A: leite integral + ração Inicial.

B: leite integral + ração inicial com fibra incorporada utilizando-se de polpa citrica desidratada.

C: leite integral + ração inicial com $20 \%$ de feno de graminea (Coastcross, Cynodon dactilon) triturado e incorporado.

D: leite integral + ração inicial + feno de graminea triturado (Coastcross, Cynodon dactilon) oferecido separadamente, "ad libitum".

A composição percentual das rações é apresentada na tabela 01 .

Tabela 01 - Composição percentual das raçōes experientais (com base na matéria seca)

\begin{tabular}{lccc}
\hline Ingrediente & tratamento A & tratamento B & tratamento C \\
\hline Fubá de milho & 47,54 & 18,83 & 46,55 \\
Polpa cítrica & - & 35,14 & - \\
Feno & - & - & 20,00 \\
F. soja 46\% & 17,94 & 18,85 & 15,63 \\
F. trigo & 24,30 & 20,00 & 10,00 \\
C. calcitico & 3,08 & - & 1,48 \\
F. bicalcíco & 1,14 & 1,18 & 0,34 \\
Leite em pó & 5,00 & 5,00 & 5,00 \\
desnatado & & & \\
Sal mineral & 1,0 & 1,0 & 1,0 \\
\hline Total & 100,00 & 100,00 & 100,00 \\
\hline
\end{tabular}


$O$ tratamento $D$ constituiu-se da ração fornecida no tratamento $A$ acompanhada de feno fornecido à vontade separadamente.

( ${ }^{*}$ Niveis de garantia por quilograma de produto:

Fósforo: $80,7 \mathrm{~g}$;

Cobre: $1500 \mathrm{mg}$;

Cálcio: $140 \mathrm{~g}$;

Magnésio: $2640 \mathrm{mg}$;

Ferro: $1300 \mathrm{mg}$;

Zinco: $2588 \mathrm{mg}$;
Cobalto: $200 \mathrm{mg}$;

lodo: $195 \mathrm{mg}$;

Manganês: 1200 mg;

Selênio: 9 mg;

Os bezerros apresentaram média de peso inicial de $37,7 \mathrm{kgs}$.

Os bezerros foram criados em cabanas individuais de madeira com área $1,55 \mathrm{~m}^{2}$, com comedouro para arraçoamento e encaixe para baldes de aleitamento e de água. A cama dos bezerros foi feita de maravalha de madeira.

A análise bromatológica das raçōes iniciais é apresentada na tabela

02.

Tabela 02 - Composição bromatológica das raçōes iniciais em base seca.

\begin{tabular}{|c|c|c|c|c|c|c|c|c|c|c|c|}
\hline & $\overline{M S}$ & PB & $\overline{F B}$ & FDA & FDN & $\overline{E E}$ & $\overline{M M}$ & $\overline{E N N}$ & $\overline{\text { NDT }}$ & $\mathrm{Ca}$ & $P$ \\
\hline$A$ & 89,84 & 19,61 & 6,53 & 9,97 & 27,75 & 4,95 & 7,92 & 60,99 & 83,13 & 1,68 & 0,48 \\
\hline$B$ & 89,96 & 18,64 & 9,86 & 11,46 & 31,68 & 4,61 & 8,48 & 58,41 & 79,41 & 1,52 & 0,66 \\
\hline C & 90,16 & 17,77 & 11,02 & 10,51 & 38,91 & 3,72 & 7,90 & 59,59 & 78,01 & 1,17 & 0,44 \\
\hline & $\begin{array}{l}\text { *Obtid } \\
{ }^{\star \star} \text { Estin } \\
\text { AND } \\
\text { A pol }\end{array}$ & $\begin{array}{l}\text { o por di } \\
\text { nado } \\
\text { RIGUET } \\
\text { pa cítri }\end{array}$ & $\begin{array}{l}\text { erença. } \\
\text { em fu } \\
\text { To et. } \\
\text { ca utili }\end{array}$ & $\begin{array}{l}\text { Inçāo } \\
\text { al.(198 } \\
\text { zada }\end{array}$ & $\begin{array}{l}\text { da } \\
\text { ). } \\
\text { oi o }\end{array}$ & & & bromatol & $\begin{array}{l}\text { lógica } \\
\text { pelet }\end{array}$ & & \\
\hline
\end{tabular}


análises bromatológicas do feno e da polpa citrica, obtidos na ocasião. Os resultados são apresentados na tabela 03 .

Para verificar os efeitos dos tratamentos, foram tomados, o peso e altura de cernelha a cada 7 dias e controle diario de ingestão de alimentos.

As pesagens foram realizadas após ter sido ministrado o leite pela parte da manhã, utilizando-se uma balança mecânica com sensibilidade para $100 \mathrm{~g}$. Para contenção dos animais utilizou-se uma gaiola de madeira.

Tabela 03 - Composição bromatológica do feno de coast-cross e polpa cítrica desidratada com base na matéria seca

\begin{tabular}{|c|c|c|}
\hline Nutriente & Polpa Cítrica & Feno de Coast-Cross \\
\hline PB & 6,45 & 13,83 \\
\hline FB & 15,42 & 32,37 \\
\hline FDN & 28,77 & 81,24 \\
\hline FDA & 33,74 & 40,68 \\
\hline EE & 3,65 & 1,52 \\
\hline$P$ & 0,11 & 0,20 \\
\hline $\mathrm{Ca}$ & 2,62 & 0,34 \\
\hline MM & 6,56 & 6,81 \\
\hline $\mathrm{ENN}^{*}$ & 67,92 & 45,47 \\
\hline NDT $^{* *}$ & 76,13 & 58,28 \\
\hline MS & 91,40 & 91,7 \\
\hline
\end{tabular}

A altura na cernelha foi tomada pela média de três mensurações consecutivas tomadas com o bezerro em posição de quadrilátero, com o emprego de uma escala graduada em centímetros, com um braço perpendicular colocado à altura da cernelha. 
Os ganhos de peso, bem como os ganhos de altura foram obtidos pela diferença entre a medida inicial (primeira tomada) e a final (última tomada).

Tomou-se diariamente, a partir da primeira pesagem do bezerro, as ofertas e sobras de concentrado para todos os animais e, em separado, das ofertas e sobras de feno do tratamento D. A conversão alimentar foi calculada pela divisão do consumo total (em quilogramas) pelo ganho de peso (em quilogramas), considerando-se também a MS fornecida pelo leite. Os consumos de MS, por quilograma de peso vivo, foram obtidos dividindose a soma dos consumos diários (diferença entre o fornecido e o recusado mais o leite) pelo pesos vivos médios (divisão da soma das pesagens, em quilogramas, pelo número destas durante o período). Os consumos de ração, por quilograma de peso metabólico, foram obtidos de modo análogo, elevando-se os pesos vivos médios à potência de $0,75\left(\mathrm{PV}^{0,75}\right)$. Também foram calculadas as ingestōes dos nutrientes de cada tratamento (MS, PB, FB, FDN, FDA, EE, ENN), com base na matéria seca, multiplicando-se a quantidade de ração ingerida, pela porcentagem de cada nutriente neste, e somando-se com o fornecido pelo leite e pelo feno, quando este foi consumido.

Houve, ainda, tomadas relacionadas à incidência de diarréias, em que se adotou a classificação mencionada por LUCCI (1989). Considerou-se a porcentagem dos dias com incidência de diarréia (notas 3 e 4) sobre 0 período total. 
Ao final do periodo de experimentação, foram tomadas medidas de capacidade ruminal com base no volume dos pré-estomagos, segundo WARNER et. al (1956), do desenvolvimento papilar, contagem de protozoários e determinação de $\mathrm{pH}$. Observou-se, ainda, de modo empírico, o padrāo de papilas da mucosa do rúmen quanto à coloração e densidade, além de aspectos relacionados à maceração e coloração do alimento.

A altura das papilas foi tomada pela média de 5 leituras consecutivas e ao acaso de um corte de $10 \mathrm{~cm}^{2}$ de tecido - com o auxilio de um paquimetro, procurando fazê-lo sempre no mesmo local anatômico (parede ventral do saco ventral do rúmen), segundo STOBO et. al (1966).

Para se proceder à análise do conteúdo ruminal (protozoários) adotou-se a técnica descrita por DEHORITY(1977), HUNGATE (1966) e NOGUEIRA FILHO (1981) utilizando-se câmara de Sedgwick-Rafter e microscópio ZEISS ${ }^{\odot}$ com ocular reticulada, com área de $0,4323 \mathrm{~mm}^{2}$, aferida por lâmina micrométrica.

$\mathrm{O} \mathrm{pH}$ ruminal foi tomado imediatamente após o abate dos animais, esvaziando-se o conteúdo ruminal em um balde plástico; homogeneizandose o material, colhendo-se uma amostra e espremendo-se o material para proceder a medida em um meio líquido. Procedimento adotado, dado que os conteúdos apresentavam-se em consistência pastosa, impossibilitando a leitura.

Para análise estatística dos dados, utilizou-se delineamento inteiramente casualisado, segundo Statistical Analyses Sistem (SAS) de 1985. Foi feito ajuste para ganho de peso, ganho em altura, consumo de 
matéria seca, conversāo alimentar e ingestōes tendo como covariável o peso inicial.

gERVICO DE BIBLIO E.AA E DOCUMENTAC:AT Faculdado de Zootecnis - Engonharle do Alimunto

Univeraldade de Sto Paule 


\section{RESULTADOS E DISCUSSÃO}

A tabela 04 corresponde às médias e aos coeficientes de variação dos parâmetros: ganho de peso diário, ganho em altura, conversão alimentar e consumo de alimentos.

Tabela 04 - Médias e coeficientes de variação dos ganhos de peso, ganho em altura total, conversão alimentar e consumo de MS diário, consumo de MS total por quilograma de peso vivo e quilograma de peso vivo metabólico.

\begin{tabular}{|c|c|c|c|c|c|c|}
\hline Trat. & $\begin{array}{c}\text { Ganho } \\
\text { de Peso } \\
\text { Diário } \\
(\mathrm{kg})\end{array}$ & $\begin{array}{l}\text { Altura da } \\
\text { cernelha } \\
\text { (cm) }\end{array}$ & $\begin{array}{l}\text { Conversāo } \\
\text { Alimentar }\end{array}$ & $\begin{array}{l}\text { Consumo } \\
\text { Diário } \\
\text { MS(kg) }\end{array}$ & $\begin{array}{c}\text { Consumo } \\
\mathrm{kg} \mathrm{MS} / \mathrm{kg} \\
\text { PV }\end{array}$ & $\begin{array}{c}\text { Consumo } \\
\mathrm{kg} \mathrm{MS/kg} \\
\mathrm{PV}^{0,75}\end{array}$ \\
\hline \multirow[t]{2}{*}{ A } & $0,226^{b}$ & $5,033^{a}$ & $2,591^{a}$ & $0,558^{b}$ & $0,752^{D}$ & $1,939^{\mathrm{b}}$ \\
\hline & $(12,43)$ & $(27,38)$ & $(19,37)$ & $(18,85)$ & $(14,98)$ & $(15,45)$ \\
\hline \multirow[t]{2}{*}{ B } & $0,263^{a b}$ & $5,767^{a}$ & $2,291^{a}$ & $0,607^{\mathrm{b}}$ & $0,780^{\mathrm{ab}}$ & $2,007^{a b}$ \\
\hline & $(14,30)$ & $(27,82)$ & $(16,31)$ & $(18,59)$ & $(18,06)$ & $(17,28)$ \\
\hline \multirow[t]{2}{*}{$\mathrm{c}$} & $0,336^{a}$ & $7,617^{a}$ & $2,272^{a}$ & $0,769^{a}$ & $0,973^{a}$ & $2,506^{a}$ \\
\hline & $(17,20)$ & $(26,69)$ & $(17,45)$ & $(6,807)$ & $(5,70)$ & $(5,01)$ \\
\hline \multirow[t]{2}{*}{ D } & $0,327^{a}$ & $6,350^{a}$ & $2,359^{a}$ & $0,755^{\mathrm{a}}$ & $0,963^{a}$ & $2,483^{\mathrm{a}}$ \\
\hline & $(30,13)$ & $(23,39)$ & $(19,24)$ & $(26,86)$ & $(16,51)$ & $(18,07)$ \\
\hline
\end{tabular}

Obs 1 : Coeficientes de Variação entre parēnteses.

Obs2: Médias com a mesma letra nas colunas não diferem entre si ao nivel de $5 \%$ designificância.

As análises estatísticas acusaram diferença entre as médias dos tratamentos para o parâmetro ganho de peso diário (GPD), tendo como covariável o peso inicial (figura 01). 


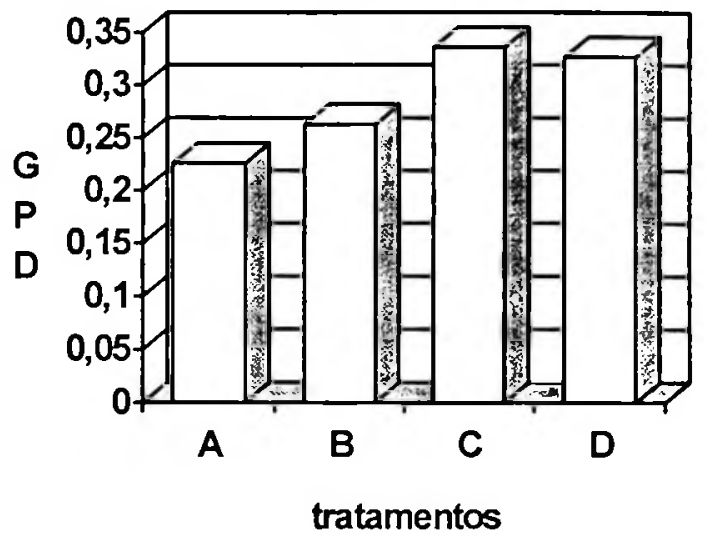

Figura 01 - Médias de ganhos de pesos diários $(\mathrm{kg})$ por tratamento corrigidos para peso inicial.

A análise não mostrou diferença significativa com relação ao ganho de peso, no que tange à forma de incorporação de fibra na ração. Os dois tratamentos com feno proporcionaram os maiores ganhos em peso: os bezerros com feno incorporado ganharam por dia aproximadamente $336 \mathrm{~g} \mathrm{e}$ os com feno "ad libitum" $327 \mathrm{~g}$, sem terem sido significativamente diferentes entre si, embora tenha sido detectada tendência $(p=0,0587)$ de diferença entre eles. $O$ pior desempenho em ganho de peso ficou para o tratamento "A", ou seja, apenas ração inicial convencional e leite. Discordando dos resultados obtidos por THOMAS \& HINKS (1982), e concordando com os de NOLLER et. al(1962). No entanto, năo foram tomadas medidas de enchimento do trato digestivo para utilização destas enquanto covariável, como sugere o trabalho de JAHN et. al (1970). 
Näo se observou a presença de maravalha de madeira (proveniente da cama dos bezerros), no bolo alimentar, nem aderido às paredes dos órgāos do trato digestivo, excluindo a possibilidade de que a ingestāo de maravalha tenha interferido nos resultados do experimento.

Os consumos de MS, quilograma de consumo de matéria seca por quilograma de peso vivo médio, e por quilograma de peso metabólico médio, também apresentaram diferenças significativas (figura 02), sendo os consumos das dietas com feno superiores às demais $(P<0,05)$

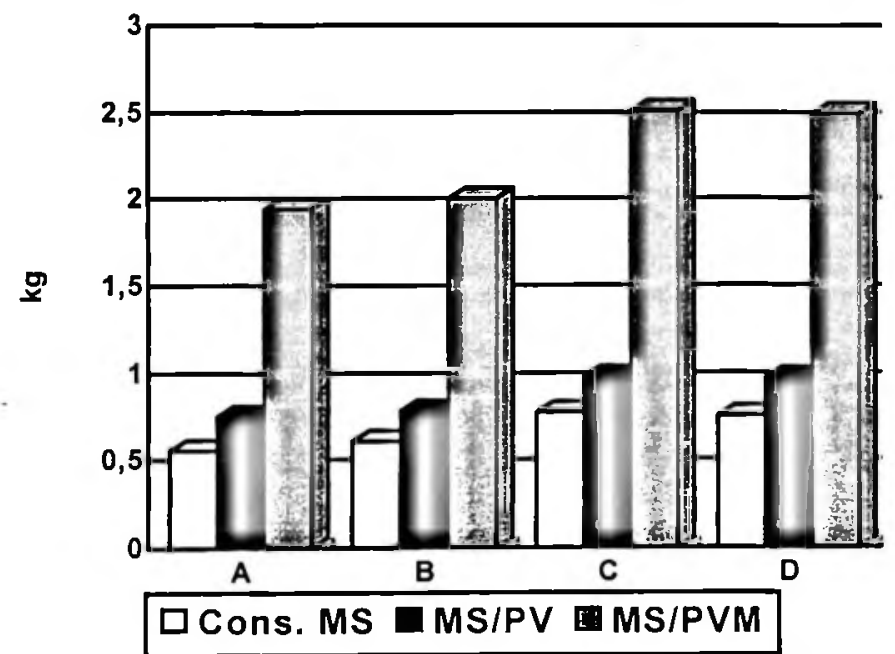

Figura 02 - Consumo de matéria seca total (kg), consumo de matéria seca por $\mathrm{kg}$ de peso vivo médio e consumo de matéria seca por kg de peso metabólico médio.

NOLLER et. al (1962) não encontraram diferença no ganho de peso até os 70 dias de idade em bezerros consumindo dietas com feno incorporado (embora com maior consumo de feno, em detrimento do menor consumo de grãos e matéria seca total); concluindo que o feno não precisa ser forçado a ser consumido à idade tenra, conquanto possa ser utilizado. 
Em outro experimento, THOMAS \& HINKS (1983) também nāo obtiveram diferenças significativas no desempenho entre tratamentos, considerando de zero (0) até $320 \mathrm{~g}$ de feno incorporado. No entanto, os autores justificam esta ausência de significância como um efeito da redução do conteúdo de proteína bruta e energia abaixo do nível mínimo aceitável. Com o conseqüente efeito de que as respostas obtidas pudessem estar refletindo uma inadequadabilidade ao suprimento nutricional, anterior ao efeito que o aumento do nivel de fibra possa ter causado. Observou-se porém que, no presente estudo, comparando-se os valores atingidos para ganho de peso diário com aquele citado por LUCCI (1989), o tratamento em que a fibra foi incorporada à ração, na forma de volumoso, foi o que mais se aproximou daquele indice e que obteve maior valor. Os resultados encontrados são parcialmente concordantes aos obtidos por THOMAS \& HINKS (1982), estes autores encontraram significância estatística $(p<0,05)$, embora com animais com idade inicial de 5 semanas até 9 semanas, ao compararem a dieta basal (sem a presença de feno de cevada) com dietas com feno inteiro ou moído "ad libitum" separadamente e uma quarta dieta com feno moído incorporado. Estes observaram maiores ganhos de peso e ingestāo de matéria seca, naquela ração em que houve a incorporação do feno ao concentrado. Ainda uma quinta dieta incorporou ao concentrado basal um tamponante que obteve resultados semelhantes ao obtido à dieta com feno moído "ad libitum", separadamente.

No presente experimento, os niveis de proteina bruta foram menores para as raçōes com maiores niveis de fibra bruta. Deste modo, poderia 
esperar-se que a conversão fosse pior para estas rações, pois segundo HOGUE et. al (1956), animais jovens tiveram dificuldade em aproveitar o nitrogênio da dieta. Contudo, nas condiçōes do presente experimento, observou-se que a conversão alimentar foi melhor para niveis de proteina menores, dentro do concentrado, pois a conversão variou de 2,59 para ração inicial e leite, a 2,27 para a ração com feno incorporado. LUCCI (1976 $a, b)$, em experimento de arranjo fatorial com niveis de proteina, observou menores indices de conversão de MS e NDT para tratamentos com maiores niveis energéticos, em que se evidenciou não haver influência dos niveis de proteina digestivel na eficiência de aproveitamento de matéria seca e nutrientes digestiveis totais, resultados estes concordantes com TRAUB \& KESLER (1972) e que ajudam a justificar a ausência de um melhor resultado de conversão de nutrientes pelos animais submetidos ao tratamento " $A$ " no presente estudo, com base nos niveis energéticos. Porquanto, os niveis de energia e proteina, dentro da ração " $A$ ", foram balanceadas para serem maiores. Embora os tratamentos " $C$ " e " $D$ " tenham apresentado maiores ingestões de NDT. ELLIS \& PFANDER (1958) verificaram que se diminui a digestibilidade da matéria seca ao utilizar-se $21,4,31,4$ e $41,6 \%$ de celulose semi-purificada, bem como dos ENN e NDT; atribuindo tal efeito ao conceito de "envelopamento" causado pela celulose, que diminuiria a digestibilidade dos outros nutrientes com o aumento da concentração de celulose. Como trabalhamos com diferentes formas de arraçoamento resultando em diferentes niveis de ingestāo de agentes "envelopantes" estes poderiam também ter influenciado o resultado. 
Podemos também, por outro lado, utilizar o mesmo tipo de raciocínio acima quanto ao nivel de carboidratos solúveis. Se nos reportarmos ao trabalho de CHAPPELL \& FONTENOT (1968), verificamos que os autores constataram que a composição em carboidratos prontamente solubilizáveis no rúmen tiveram influência na digestibilidade de proteinas, diminuindo a fração nitrogenada da urina.

O fato é que, no pressente estudo, estatisticamente houve diferença entre os ganhos de peso, nos consumos de matéria seca e nas ingestões de vários dos nutrientes que compōem os tratamentos. Pode-se justificar um consumo maior de rações com niveis fibrosos maiores, e niveis de energia e proteina menores, através de uma maior ingestão de nutrientes, em compensação àquelas rações onde ocorre o contrário (niveis de fibra menores com maior concentração de proteina e energia). Os efeitos dos niveis de cada nutriente dentro do experimento necessita de maiores informações para se chegar alguma conclusão.

Os resultados dos cálculos das quantidades de nutrientes ingeridos por tratamento apresentam-se na tabela 05 ( e estão ilustrados nas figuras de 3 e 4), não havendo diferenças, a $5 \%$ de significância, entre os tratamentos na ingestão de $E E$, embora tenha sido verificada tendência $(p<0.051)$, proveniente principalmente do leite fornecido. Observa-se que, para a maioria dos nutrientes, houve maior ingestāo nos tratamentos " $\mathrm{C}$ " $\mathrm{e}$ "D". Também foi verificado um maior consumo de FDA para o tratamento "D". JAHN et. al (1970), em experimento realizado com animais de 8 a 23 semanas de idade, observaram que houve um aumento no consumo 
voluntário de fibra, alcançando um máximo aproximadamente com $23 \%$ de FDA. Observa-se, igualmente, que todos os niveis de ingestão de FDA estiveram abaixo daqueles determinados por JAHN et. al (1970). No experimento de JAHN et. al (1970) a digestibilidade da matéria seca aproximou-se de $70 \%$ a este nível de fibra. Em niveis mais baixos de fibra aparentemente este consumo foi regulado por outros mecanismos, que não a digestibilidade. Concluindo-se que os fatores físicos e fisológicos de regulação do consumo de alimentos mudam de importância com o aumento da digestibilidade. Em baixos niveis de digestibilidade, são: peso corporal (refletindo a capacidade de ingestão de volumoso), resíduos indigestíveis por unidade de peso vivo por dia (refletindo a taxa de passagem) e a digestibilidade da matéria seca. Em altos níveis de digestibilidade, o consumo parece ser dependente da importância metabólica, produção e digestibilidade. De acordo com os resultados de JAHN et. al (1970) o(s) mecanismo(s) esta(ão) associado(s) com o consumo de matéria seca digestivel ou outro(s) fator(es) relacionados. BUSH (1990) afirmou que a porcentagem da parede celular, na forragem, esteve negativamente relacionada ao seu consumo voluntário, explicando parcialmente o maior consumo de feno alfafa, do que feno de "thymoti" em seu experimento. Há necessidade de esclarecimentos no que se refere ao nivel de máxima digestibilidade de matéria seca, para animais de idade mais jovem do que os utilizados nos experimentos de CONRAD et. al(1964) e JAHN et. al (1970). A determinação do ponto de inflexão da curva de consumo voluntário foi de dificil determinação, no caso em questão, uma vez que os 
animais até a referida tenra idade encontram-se em fase de transição anatômica e fisiológica.

A média de consumo total de feno no tratamento que foi fornecido separadamente correspondeu à $4,54 \mathrm{~kg}$ - com consumo médio diário de $0,079 \mathrm{~kg}$ e coeficiente de variação $79,31 \%$ - em matéria seca e para o tratamento em que o feno foi incorporado ao concentrado foi $5,86 \mathrm{~kg}-0,103$ $\mathrm{kg}$ de consumo médio diário e coeficiente de variação de $11,51 \%$ - de matéria seca (figura 05). Resultados que, segundo o trabalho de THOMAS \& HINKS (1982), inversamente proporcionais ao consumo de concentrado, em termos de quilogramas de feno por quilograma de matéria seca, significando que o feno passa a ocupar um percentual da MS ingerida.

Tabela 05 -Ingestão total de nutrientes $(\mathrm{kg})$ em base seca e seus respectivos coeficientes de variação

\begin{tabular}{ccccccccc}
\hline Trat & PB & NDT & FB & FDN & FDA & EE & MM & ENN \\
\hline A & $7,200^{\mathrm{b}}$ & $31,380^{\mathrm{c}}$ & $1,230^{\mathrm{b}}$ & $5,040^{\mathrm{b}}$ & $4,860^{\mathrm{c}}$ & $5,070^{\mathrm{a}}$ & $2,290^{\mathrm{c}}$ & $16,350^{\mathrm{b}}$ \\
& $(17,37)$ & $(16,05)$ & $(29,23)$ & $(29,23)$ & $(29,24)$ & $(10,31)$ & $(20,28)$ & $(20,69)$ \\
& & & & & & & & \\
B & $7,620^{\mathrm{ab}}$ & $32,88^{\mathrm{bc}}$ & $2,090^{\mathrm{ab}}$ & $6,760^{\mathrm{b}}$ & $2,440^{\mathrm{bc}}$ & $4,860^{\mathrm{a}}$ & $2,620^{\mathrm{bc}}$ & $18,650^{\mathrm{b}}$ \\
& $(18,56)$ & $(16,29)$ & $(25,83)$ & $(25,82)$ & $(25,83)$ & $(12,85)$ & $(18,79)$ & $(22,27)$ \\
$\mathrm{C}$ & $9,030^{\mathrm{a}}$ & $39,280^{\mathrm{a}}$ & $3,260^{\mathrm{a}}$ & $11,070^{\mathrm{a}}$ & $3,130^{\mathrm{b}}$ & $5,030^{\mathrm{a}}$ & $3,260^{\mathrm{a}}$ & $25,440 \mathrm{a}$ \\
& $(6,16)$ & $(6,09)$ & $(11,53)$ & $(18,98)$ & $(11,53)$ & $(9,47)$ & $(7,14)$ & $(9,126)$ \\
& & & & & & & & \\
D & $9,110^{\mathrm{a}}$ & $38,89^{\mathrm{ab}}$ & $3,100^{\mathrm{a}}$ & $10,700^{\mathrm{a}}$ & $4,350^{\mathrm{a}}$ & $5,150^{\mathrm{a}}$ & $3,150^{\mathrm{ab}}$ & $24,780^{\mathrm{a}}$ \\
& $(24,70)$ & $(22,01)$ & $(40,43)$ & $(36,64)$ & $(38,57)$ & $(11,33)$ & $(28,95)$ & $(32,88)$
\end{tabular}

$\mathrm{Obs}_{1}$ : Coeficientes de variação entre parénteses.

$\mathrm{Obs}_{2}$ : Médias com a mesma letra nas colunas náo diferem entre si ao nivel de $5 \%$ de significância. 
Entre os tratamentos "C" e "D", o consumo médio de feno por quilograma de matéria seca não apresentou diferença significativa - cento e dezoito gramas por quilograma de MS (118g/kg MS) e noventa e cinco gramas por quilograma de MS (95g/kg MS) respectivamente. 0 s consumos de matéria original aos 60 dias de idade corrigidos para peso inicial apresentaram diferença significativa (Tabela 06). Verficaram-se diferenças significativas para os tratamentos " $C$ " e " $D$ " em relaçāo ao tratamento " $A$ ", e tendência de diferença no consumo de alimentos aos 60 dias entre os tratamentos "B" e "D" $(p=0,0811)$.

Tabela 06 - Médias diárias de consumo de alimentos sólidos ( $\mathrm{kg})$ na matéria original e seus respectivos coeficientes de variação ao final do experimento.

\begin{tabular}{cc}
\hline Tratamento & Consumo de Alimento $(\mathrm{kg})$ \\
\hline A & $0,895^{\mathrm{b}}$ \\
& $(14,054)$ \\
B & $1,117^{\mathrm{ab}}$ \\
& $(14,347)$ \\
C & $1,328^{\mathrm{a}}$ \\
& $(29,400)$ \\
D & $1,484^{\mathrm{a}}$ \\
& $(34,220)$
\end{tabular}

Obs 1 : Coeficientes de Variaçăo entre parènteses.

Obs2: Médias com a mesma letra nas colunas não diferem entre si ao nivel de $5 \%$ ) de probabilidade. 


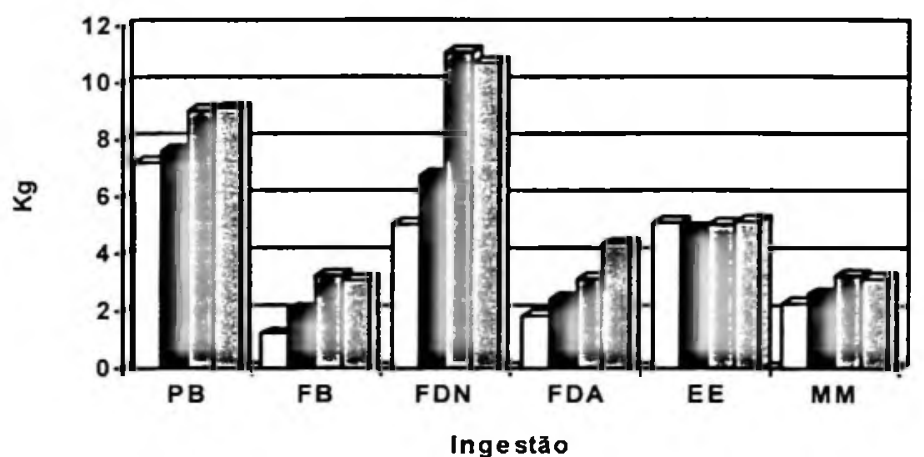

\section{$\square A \square B$ B}

Figura 03 - Ingestão total de nutrientes $(\mathrm{kg})$ - proteína bruta, fibra bruta, fibra em detergente neutro, fibra em detergente ácido, e extrato etéreo.

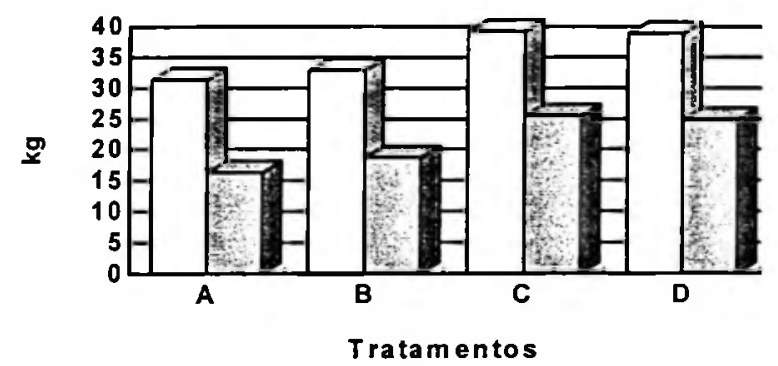

\section{$\square \operatorname{lng}$. NDT $\square \operatorname{lng}$. ENN}

Figura 04 - Ingestão total de nutrientes $(\mathrm{kg})$ - nutrientes digestiveis totais e extrativos não nitrogenados.

Apesar do consumo diário, aos 60 dias, ter variado entre os tratamentos, de $0,895 \mathrm{~kg}$, no tratamento " $\mathrm{A}$ ", até $1,484 \mathrm{~kg}$, no tratamento " $\mathrm{D}$ ", todos seriam suficientes para efetuar um desaleitamento precoce sem problemas naquela idade. 
O maior consumo total de alimento para os tratamentos com feno em comparação aos outros tratamentos foi uma função principalmente do aumento do consumo de feno (figura 05). Em concordância ao trabalho de THOMAS \& HINKS (1982), em que a presença do feno demonstrou significância para o consumo de matéria seca, no entanto, diferindo dos resultados obtidos no presente trabalho, em que 0 autor obteve significância entre os tratamentos que incorporaram ou não o feno na ração.

A incidência de diarréias também não apresentou diferença significativa entre os tratamentos.

O desenvolvimento do retículo-rúmen depende do acesso à fibra. Assim, no tratamento "B", no qual utilizou-se a polpa citrica esse desenvolvimento pode ter sido prejudicado uma vez que ela foi composta principalmente de pectina; a qual segundo CARVALHO (1995) foi prontamente solubilizável no rúmen de um animal adulto.

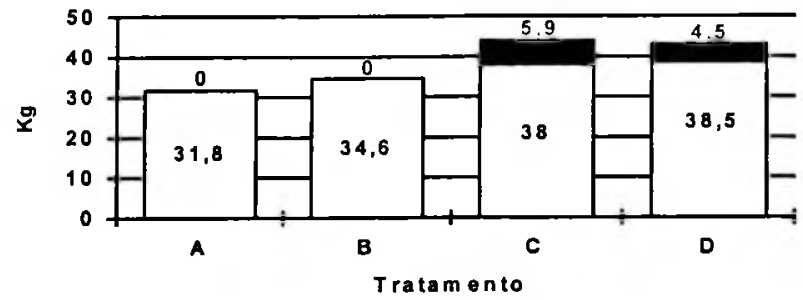

$\square$ Concentrado (MS) DFeno (MS)

Figura 05- Ingestăo total de matéria seca em quilogramas - feno e concentrado 
Observa-se, na tabela 7 ; ilustrada na figura 6 , que as proporçōes volumétricas relativas dos conjuntos rúmen+retículo e omaso+abomaso, assumiram características de um animal adulto, e que estes animais atingiram condiçōes de comportarem-se fisiológicamente como tal, segundo CHURCH (1979). Apesar de não haver diferença significativa, o maior volume ruminal foi obtido no tratamento com feno incorporado $(85,48 \%)$ e o menor para a dieta sem fibra suplementar $(78,97 \%)$. Estes volumes diferentes talvez possam explicar a maior ingestão de matéria seca pelos bezerros que consumiram feno. Os métodos utilizados para mensuração volumétrica foi criticado por STOBO et. al (1966), uma vez que, segundo estes, logo que o tônus muscular foi perdido, as paredes dos órgãos podem se tornar capazes de considerável distensão; particularmente se há um lapso de tempo entre o abate do animal e a mensuração da capacidade volumétrica. Fato que não ocorreu no presente estudo. Existem metodologias, como a proposta por FLATT et. al (1959), que utilizam-se do animal "in vivo" e que, provavelmente, fornecem uma medida mais precisa do volume reticulo-ruminal. No entanto, esta também foi passivel de crítica, uma vez que, como justificam os próprios autores, parte da diferença entre a capacidade determinada "post mortem" pode estar comprometida pela presença de bolsas de ar no retículo-rúmen durante determinações "in vivo". Como estes autores relataram que a performance de bezerros fistulados, alimentados com dietas secas, foi menor que em animais intactos, por causa da ausência de cânula. Parece que o método utilizado em nosso estudo para capacidade volumétrica foi mais satisfatório, tendo em mente 
que os valores obtidos foram usados para propósitos comparativos, pois como no trabalho de STOBO et. al (1966) utilizou-se de apenas uma técnica e não duas como o que ocorreu no trabalho de FLATT et. al (1959). Com relação ao tamanho das papilas ruminais - tabela 7, figura 7 novamente a estatística nāo demonstrou diferenças significativas, que poderiam ser explicadas pelo elevado coeficiente de variação. Por outro lado, LUCCI (1976 b) relatou não haver relação aparente da altura das papilas com o consumo de concentrado, mas, sim, com a ingestão de MS. No presente caso, o fato de nāo haver diferenças significativas entre a altura das papilas ruminais, e não obstante a análise de consumo de matéria seca apresentar diferença significativa: a análise de comprimento de papilas (tendo como covariável o consumo de matéria seca) não mostraram diferenças significativas entre os tratamentos (sequer observou-se tendência). THOMAS \& HINKS (1982) fundamentaram-se no fato de que maiores proporçōes de AGVs, principalmente os ácidos butírico e propiônico, foram responsáveis pelo desenvolvimento papilar. Registraram, ainda, que no caso de haver maior estímulo à ingestão de concentrado, pela presença de volumosos (como verificou-se no trabalho dos mesmos), o tamanho das papilas foi estimulado pela maior proporção estequiométrica destes ácidos. 
Tabela 07- Média do percentual volumétrico do $R-R$ (rúmen-retículo), O-A (omaso-abomaso), $\mathrm{pH}$, e altura das papilas tomadas com paquímetro e seus respectivos coeficientes de variação.

\begin{tabular}{ccccc}
\hline & $\begin{array}{c}\text { volume R-R } \\
(\%)\end{array}$ & $\begin{array}{c}\text { volume O-A } \\
(\%)\end{array}$ & $\begin{array}{c}\text { papilas } \\
(\mathrm{mm})\end{array}$ & $\mathrm{pH}$ \\
\hline A & $78,97^{\mathrm{a}}$ & $21,03^{\mathrm{a}}$ & $2,175^{\mathrm{a}}$ & $6,29^{\mathrm{a}}$ \\
& $(8,83)$ & $(33,16)$ & $(24,451)$ & $(14,94)$ \\
B & $81,31^{\mathrm{a}}$ & $18,69^{\mathrm{a}}$ & $1,985^{\mathrm{a}}$ & $5,87^{\mathrm{a}}$ \\
& $(10,45)$ & $(45,45)$ & $(33,714)$ & $(20,11)$ \\
C & $85,48^{\mathrm{a}}$ & $14,51^{\mathrm{a}}$ & $2,212^{\mathrm{a}}$ & $6,76^{\mathrm{a}}$ \\
& $(8,53)$ & $(50,24)$ & $(41,281)$ & $(4,56)$ \\
& $79,80^{\mathrm{a}}$ & $20,20^{\mathrm{a}}$ & $1,745^{\mathrm{a}}$ & $6,48^{\mathrm{a}}$ \\
& $(14,36)$ & $(56,74)$ & $(34,11)$ & $(8,02)$
\end{tabular}

Obs1: Coeficientes de variação entre parênteses

Obs2: Médias com a mesma letra nas colunas não diferem entre si ao nivel de $5 \%$ de probabilidade. 


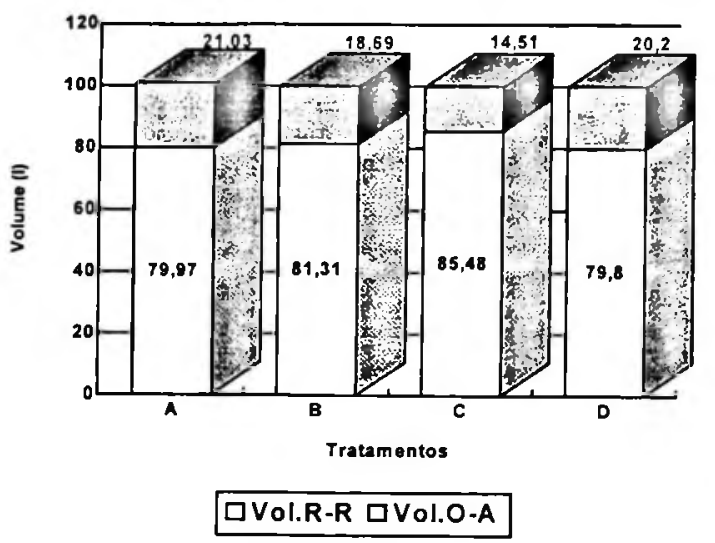

Figura 06 - Proporçōes volumétricas relativas dos conteúdos rúmen-reticulo e omaso-abomaso.

O constatado foi que tanto os tratamentos com maiores niveis de fibra, quanto o tratamento sem fibra extra, obtiveram ingestões suficientes de concentrado para produzirem AGVs em quantidade que estimulasse a mucosa da parede do rúmen. Foram observadas ocorrências de aglomeramento de papilas e escurecimento da mucosa da parede ruminal, para aquela ração em que o nivel de fibra foi fixada em $5 \%$; bem como para a ração que utilizou-se de polpa citrica, mostrando que, sob esta ótica, este tipo de arraçoamento não seria indicado, por periodos muito prolongados. Quanto à maceraçāo do alimento do conteúdo rúmino-retícular, mostrou-se homogêneo para todos os tratamentos. Mesmo sendo um parâmetro tomado grosseiramente, uma vez que as rações eram homogêneas e o feno pré-moído, pode-se dizer que, até a idade experimental dos bezerros ao final, para os niveis de ingestão de fibra, não houve problemas quanto à formação de placas ou paraqueratose. Embora, como citado anteriormente, pôde-se observar uma tendência de aglomeramento de papilas no caso das 
raçōes "A" e "B". MORISSE et. al (1992) evidenciaram que a caracteristica "pigmentação-queratinização" foi uma adaptação ao regime alimentar hiperenergético, sendo a mesma compativel com um crescimento médio elevado. Entretanto os animais nos quais a característica "pigmentaçăoqueratinização" foi mais forte, tiveram um ganho de peso muito elevado entre 6 e 10 meses $(p<0,001)$, associado a uma diminuição de desempenhos mais importante em periodo de acabamento $(p<0,05)$. Estando estabelecido que o nivel de depósitos adiposos, sobre a carcaça, está largamente condicionado pelas possibilidades de crescimento do animal, em período de acabamento (13-16 meses): as consequências econômicas da hiperqueratose do rúmen podem ser mais importantes, do que a simples análise do crescimento médio deixaria supor. No entanto, no presente estudo, os maiores ganhos de peso observados foram exatamente naqueles animais, em que os niveis de energia da ração foram menores enquanto os niveis de fibra foram maiores. Apesar de não haver diferença significativa para altura das papilas (e a observação de formação de placas e aglomeramento de papilas ter sido empírica), pode-se supor que a diferença esteja no efeito "escarificante" e estimulador de movimentos que a presença da fibra na dieta permitiu. Pois propicia uma parede mucosa do rúmen mais limpa e saudável, facilitando a absorção de nutrientes e um melhor aproveitamento destes. 


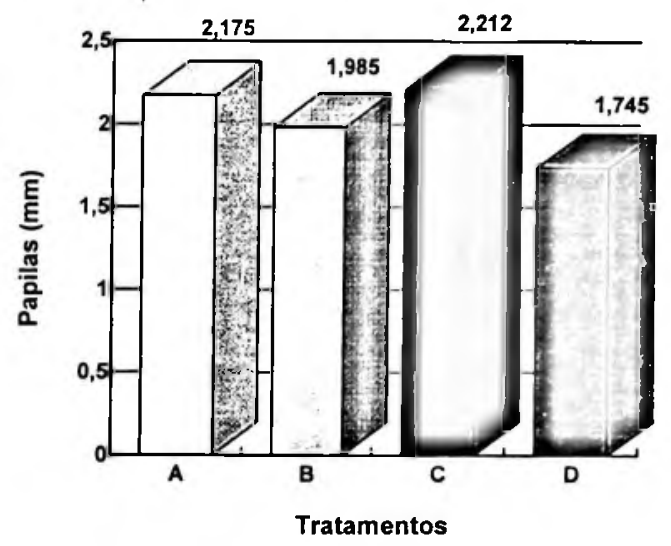

Figura 07 - Altura das papilas da parede do rúmen (mm) - saco ventral

Quanto à coloração de conteúdo ruminal, os tratamentos " $C$ " e " $D$ " apresentaram conteúdo esverdeado, enquanto os tratamentos " $A$ " e " $B$ " apresentaram conteúdo amarronzado. Segundo LUCCI (1976a, b), a cor esverdeada do conteúdo ruminal dos tratamentos " $C$ " e "D" pode ser explicada pelo maior consumo de feno total durante os últimos dias de vida.

Segundo SCHAIBLY \& WING (1974), a pectina tem característica fermentativa produtora de ácido acético, que foi um ácido fraco (com baixo potencial hidrogeniônico), no entanto, apesar de nāo existirem diferenças significativas - tabela 7 , figura 8 - o pH da dieta "B", com polpa citrica na dieta ao redor de $35 \%$ foi o menor - 5,8 - sugerindo uma produção acentuada de ácidos, carcterística de rações ricas em concentrados. 


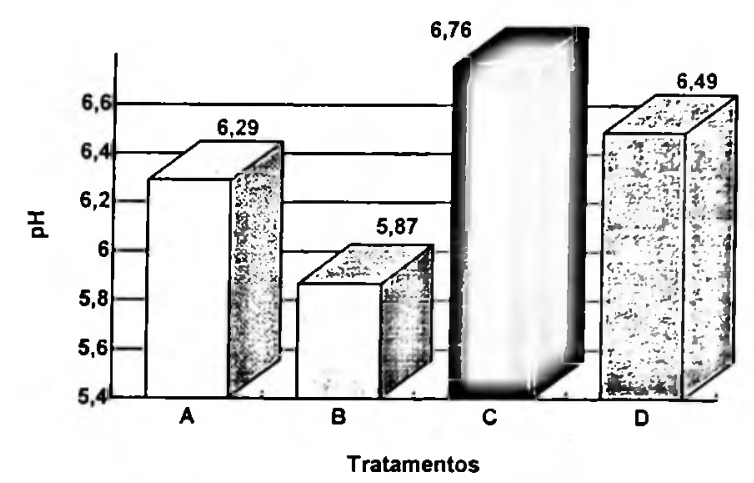

Figura 08 - pH do conteúdo ruminal.

Para THOMAS \& HINKS (1982) a causa do melhor desempenho das raçōes, contendo fibras, deve-se à capacidade tamponante. Segundo os autores, ○ pH mais elevado (propiciado pela presença da fibra na dieta) seria indiretamente responsável pela maior capacidade de ingestão de alimento e ganho de peso, uma vez que previne a hiperacidose.

A hiperacidose foi inibidora do consumo voluntário de alimento (nutrientes), indicando que a capacidade tamponante "do rúmen" (influenciado pela dieta), foi certamente de importante significado para os bezerros jovens. Assume, pois, igual importância àquela da "teoria da energia constante", na justificativa da variação do consumo entre os tratamentos. Considerando-se 6 , ou outro valor superior, o pH indicado, conforme EADIE et. al (1967), a capacidade de ingestão parece ter sido limitada pelo enchimento do trato digestivo, bem como o maior ganho de peso. Em tratamento com forragem incorporada, isto provou-se no trabalho de THOMAS \& HINKS (1982. Enfatizando-se o maior enchimento, porporcionado pelo $\mathrm{pH}$ mais alto e conseqüente maior ingestāo. Pelo fato de 
a polpa cítrica ter sido obtida, sob a forma de peletes, houve necessidade de moagem da mesma, produzindo grãos de até $1 \mathrm{~mm}$, sem utilizar-se de peneira no moedor, para homogeneizar-se a ração em que esta foi usada. $O$ mesmo foi feito com o feno utilizado nos tratamentos " $C$ " e " $D$ ", produzindo fibras de até $1,5 \mathrm{~cm}$ de comprimento. Com a moagem, reduz-se fisicamente o tamanho da fibra, influenciando-se o tempo de permanência da mesma no rúmen e diminuindo-se sua efetividade para atuar como tamponante. Os resultados obtidos por THOMAS \& HINKS (1982) sugeriram que a moagem do feno não alterou a característica de tamponamento do rúmen pela fibra; embora seja necessária uma maior quantidade desta, quando moída, para se obter os mesmos resultados que aqueles obtidos pela fibra inteira. Devese ter em mente que os animais eram pré-ruminantes e o momento era de transição; apresentando características intermediárias entre "não ruminante" e ruminante.

BROWNLEE(1956) relatou que o peso da mucosa não foi relacionado ao peso do músculo na parede do rúmen. Em seu experimento, bezerros recebendo concentrado tiveram menor musculatura da parede ruminal $e_{\text {, }}$ consideravelmente, mais mucosa em seus rúmens que aqueles que receberam feno. Como a mucosa do rúmen não foi separada da camada de músculo, em nosso experimento, o peso dos compartimentos não foram considerados, como parâmetros de avaliação. BROWNLEE (1956) também justificou a não adoção do peso do rúmen, demostrando que bezerros mantidos na dieta, exclusivamente de leite, aumentaram o peso do rúmen como um todo (algo em torno de seis vezes seu peso ao nascimento sem o 
correspondente desenvolvimento papilar). Assim o desenvolvimento da musculatura do rúmen não ocorre "pari passu" com o desenvolvimento papilar.

Não foi possivel a formulação das raçōes através dos niveis de FDN, devido à dificuldade de se determinar as necessidades dos animais. Devese considerar que, no caso de determinação da Fibra em Detergente Neutro, a polpa citrica pode ter seus níveis fibrosos subestimados (pelo menos no que diz respeito a pré-ruminantes), uma vez que a metodologia de determinaçāo de FDN, segundo MAYNARD (1984) solubiliza a pectina. Outrossim, observa-se que para polpa citrica, por problemas metodológicos, a FDA pode assumir valores superiores a FDN, o que teoricamente foi impossivel, dificultando a estimativa destes e, por conseqüência, a formulação nestas bases. Segundo VAN SOEST (1982) o detergente-neutro solubiliza a pectina, mais sílica e tanino, enquanto o detergente-ácido recupera a sílica, complexos tanino-protéicos e, em parte, a pectina. Os residuos do detergente-ácido são normalmente menores que os resíduos do detergente neutro. A influência destes efeitos, segundo aquele, na estimativa de hemicelulose, são obtidos por diferença. No caso da polpa cítrica, que foi solubilizada na determinação de FDN e que pode ser recuperada parcialmente em FDA, se a porção de pectina a ser recuperada for maior do que a de residuos recuperados, mais a hemicelulose solubilizada, o valor de FDA será maior que FDN.

A contagem de protozoários foi nula para todos os animais de todos os tratamentos, o que está de acordo com o obtido por NOGUEIRA FILHO 
(1981); mas em desacordo com os resultados obtidos para a idade dos bezerros nos trabalhos de VALVASORI et. al (1992) e LENGEMANN \& ALLEN (1955) aos 2 meses de idade. No entanto, para os tratamentos em que houve utilização de feno, observa-se valores de $\mathrm{pH}$ suficientemente altos para que haja presença de protozoários. A ausência de protozoários, podem ter explicação no fato de os animais do experimento não terem contato com animais adultos ou com alimentos que tenham entrado em contato com animais adultos. 


\section{CONCLUSŌES}

Com base nos resultados obtidos pôde-se concluir que:

1.- A utilização de polpa citrica como fonte de fibra teve resultados semelhantes aos obtidos coma ração convencional.

2. - O tratamento com feno incorporado ao concentrado foi o que apresentou melhores resultados de desempenho animal.

3. - Os efeitos dos niveis de cada nutriente dentro do experimento necessitam de maiores informaçōes para se chegar a alguma conclusão. 


\section{REFERÊNCIAS BIBLIOGRÁFICAS}

ANDERSON, K.L. et. al. Ruminal metabolic development in calves weaned conventionally or early. J. Dairy Sci., v.70, p.1000-5, 1987.

ANDRIGUETTO, J.M. et. al. Nutrição animal. São Paulo, Nobel, 1984. Cap.4, p.211-12: Gado Leiteiro.

ASH, R.W. et. al. Simulation and inhibition of reticulum contrations, rumination an parotid secration from the forestomacth of conscious sheep. J. Physiol., v.149, p.43, 1959.

BARTLEY, E.E. Bovine Saliva: production and function. In: WEINBERG, M.S.; SCHEFFER, A.L., eds. Buffers in ruminant physioloby and metabolism, Church \& Dwight Company, N.Y., 1976, p.61-77, apud MURPHY. M.R.; KENNEDY. P.M. Particle Dinamics, In: FORBES. J.M.; FRANCE. J. Quantitative Aspects of Ruminant Digestion and Metabolism, Cambridge, CABI, 1993, cap.4., p.87-106.

BHATTACHARYA, A.N.; HARB, M. Dried citrus pulp as a grain replacement for awasi lamb. J. Anim. Sci., v.36, n.6, p.1175-80, 1973.

BEN-GHEDALIA, D. et. al. The effects of starch-and-pectin rich diets on quantitative aspects of digestion in sheep. Animal Feed Science and Technology, v.24, p. 289-98, 1989.

BENZIE. D.; PHILIPSON. A.T. The alimentary tract of the Ruminant. Edinburgh, Oliver and Boyd, 1957.

BROWNLEE, A. The Development of rumen papillae in cattle fed on different diets. Br. Vet. J., v.112, p.369-76, 1956. 
BUSH, R.S. The effects of hay and silage on growth and rumen function in young holstein calves. Can. J. Anim. Sci., v.71, p.145-53, 1990.

BUSH, R.S. ; NICHOLSON, J.W.G The effects of weaning schedule. duration of milk feeding and fishmeal on calf performance. Can. J. Anim. Sci., v.66, p.681-98, 1986.

CARVALHO. M.P. Citrus. In: SIMPÓSIO SOBRE NUTRIÇĀO DE BOVINOS, 6., Piracicaba, 1995. Anais. Piracicaba, FEALQ, 1995. p.171-214.

CHAPPELL, G.L.M.; FONTENOT, J.P. Effect of level of readily-available carbohydrates in purified sheep rations on cellulose digestibility and nitrogen utilization. J. Anim. Sci., v.27, p.1709-15, 1968.

CHURCH, D.C. Digestive Phisiology and Nutrition of Ruminants. Corvallis, O \& B Books, 1979. Cap. 2, p.7-33: . Anatomy of the stomach of ruminants and pseudoruminants.

COLEMAN, G.S. The distribution of carboxy methylcellulase between fractions taken from the rumen of sheep containing no protozoa or one of five different protozoal populations. J. Agric. Sci., Camb., v.16, p.12127, 1986.

CONRAD, H.R. et. al. Regulation of feed intake in dairy cows. I. Change in importance of phisical and physiological factors with increasing digestibility. J. Dairy Sci., v.47, p.54-62, 1964.

DEHORITY, B.A. Classification and morphology of rumen protozoa. Ohio, Ohio Agricultural Research and Development Center, 1977. 82p. 
DIJKSTRA. J. Production and absorption of volatile fatty acids in the rumen. Livestock Production Sci., v.39, p.61-9, 1994.

DZIUK, H.E. Digestão no estômago dos ruminantes. In: SWENSON. M.J. Dukes' fisiologia dos animais domésticos. 20.ed. Rio de Janeiro, Guanabara, 1988. Cap. 20, p.281-87.

EADIE, J.M. et. al. A note on some comparisions between the rumen content of barley-fed steers and that of young calves also fed on a high concentrate ration. Anim. Prod. , v.9, p.247-50, 1967.

ELLIS, W.C.; PFANDER, W.H. The influence of varied cellulose and nitrogen levels upon ration digestibility and nitrogen balance of lambs fed semipurified rations. J. Nutrition, v.65, p.235-50, 1958.

FARIA, V.P. et. al. Polpa de laranja fresca e seca como aditivos para a ensilagem do capim elefante napier. O Solo, Piracicaba, v.64, n.1, p.417, 1972.

FEGEROS, K. et. al. Nutritive value of dried citrus pulp and its effect on milk yield and milk composition of lactanting ewes. J. Dairy Sci., v.78, p.1116-21, 1995.

FLATT, W.R. et. al. Evaluation of several techniques used in the study of developing rumen function. New York, New York State College of Agriculture, 1959. 30p.

GODFREY, N.W. The functional development of the calf. 1 - growth of stomach. J. Ag. Sci., v.57, p.173-5,1961a.

GODFREY, N.W. The functional development of the calf. 2- development of rumen function in the calf. J. Ag. Sci., v. 57, p.177-83, 1961 b. 
HARRIS JUNIOR, B ; STAPLES, C.R. Feeding by-products feedstuffs to dairy catle. Florida, Florida Cooperative extension service, 1989.

HIBS, J.W. et. al. A high roughage system for raising calves based on the early development of rumen function. I - Effect of variation in the ration on grouwth, feed consumption and utilization. J. Dairy Sci., v.36, n.7, p.717-27. 1953.

HOGUE, D.E. et. al. Digestion coeficients and nitrogen retention of young dairy calves as affected by antibiotics and avancing age. J. Anim. Sci., v. 15, n.3, p.788-93, 1956.

HUBER. S.T. Nutrição de bovinos jovens, In: SIMPÓSIO SOBRE NUTRIÇĀO de BOVINOS, 1., Piracicaba. Anais. Piracicaba, ESALQ, 1977, p.88-98.

HUNGATE, R.E. The rumen and its microbes. New York, Academic Press, 1966, 553p.

JAHN, E. et. al. Effects of fiber and ratio of starch to sugar on performance of ruminanting calves. J. Dairy Sci., v.53, p.466, 1970.

KERTZ. A. F. et. al. An early weaning calf program: sumarization and review. J. Dairy. Sci., v.62, n.1, p.1835-43, 1979.

LENGEMANN, F.W.; ALLEN, N.N. The development of rumen function in the dairy calf. I-Some characteristics of the rumen contents of cattle of various ages. J. Dairy Sci., v.38, p.651-56, 1955.

LUCCI, C.S. et. al. Desaleitamento precoce de bezerros. I - Niveis de energia e proteina nas rações iniciais. Rev. Fac. Med. Vet. Zoot. da USP, v.13, n.2, p.317-25, $1976 a$. 
LUCCI, C.S. et. al. Desaleitamento precoce de bezerros. III Desenvolvimento do rúmen. Rev. Fac. Med. Vet. Zoot. da USP, v.13, n.2, p.333-8, 1976b.

LUCCI, C.S. et. al. Desaleitamento de bezerros submetidos a dietas diferentes. II - Observações sobre o tempo de ruminação e de ingestão de alimentos. Rev. Fac. Med. Vet. Zoot. da USP, v.17, n.1/2, p.11 - 4, 1980.

LUCCI, C.S. Bovinos Leiteiros Jovens. São Paulo, Nobel/EDUSP, 1989. MACLEOD, G.K. et. al. Growth of holstein and jersey calves in response to four feeding programs in a breed-by-ration interaction study. J. Dairy Sci., v.53, n.9, p.1270, 1969.

MARSH, R. The performance of early-weaned calves offered concentrates or artificially dried grass. Anim. Prod., v.18, p.201-10, 1974.

MARTIN, J.G. et. al. Factors related to weight of dairy calves. J. Dairy Sci., v.45, p.886, 1962.

MAYNARD, L.A. et. al. Nutrição animal. 3.ed., Rio de Janeiro, Livraria Freitas Bastos, 1984. Cap.6, p.87-120: Os carboidratos e seu metabolismo.

MORISSE, J.P. et. al. Alterations de la muqueuse du rumen chez le taurillon en élevage intensif - Méthode d'appreciation rapide et conséquences zootechniques. Rec. Méd. Vét., v.168, n.1, p.17-24, 1992.

MURPHY, M.R.; KENNEDY, P.M. Particle Dinamics. In: FORBES, J.M.; FRANCE, J. Quantitative Aspects of Ruminant Digestion and Metabolism, Cambridge, CABI, 1993. Cap.4, p.87-106. 
NATIONAL RESEARCH COUNCIL (U.S.).SUBCOMMITTEE ON DAIRY CATLE NUTRITION. Nutritient requierements of dairy catle. 6 ed. rev., Washington, National Academy press, 1988. 157p.

NOGUEIRA FILHO, J.C.M. Contribuição ao estudo sobre protozoários em rúmen de bezerros de rebanhos leiteiros. São Paulo, 1981. 70 p. Dissertação (Mestrado) - Faculdade de Medicina Veterinária e Zootecnia. Universidade de São Paulo.

NOLLER, C.H. et. al. Value of hay and rumen inoculation in an early weaning system for dairy calves. J. Dairy Sci., v.45, n.2, p.197-201, 1962.

ORPIN, G.O. The role of ciliate protozoa and fungi in the rumen digestion of plant cell walls. Anim. Feed. Sci. Tecnol., v.10, n.2/3, p.121-44, $1983 / 84$.

ORSKOV, E.R.; RYLE, M. Energy nutrition in ruminants. London, Elsevier, 1990. 149p.

ROY, J.H.B. The calf. 4. ed., London, lliffe Books, 1980.

ROY, J.H.B. Studies in calf nutrition with special reference to the protective action of colostrum, PhD Thesis, University of Reading, 1956, apud STOBO, J.HB.; ROY, J.H.B.; GASTON, J.H. Rumen development in calf 1- The effect of diet containing different proportions of concentrates to hay on rumen development. British J. Nutr., v.20, p.171-91, 1966.

SANDER, E.G. et. al. The stimulatory efect of sodium butyrate and sodium propionate on the devvelopment of rumen mucosa in the young calf. J. Dairy Sci., v.42, n.7, p.7-12, 1959. 
SAS. Sas User's Guide. 5. ed. Cary. N.C., Sas Institute Inc., 1985.

SCHAIBLY, G.E. ; WING. J.M. Effects of roughage concentrate ratio on digestibility and rumen fermentation of corn silage citrus pulp rations. J. Anim. Sci., v.38, p.697, 1974

SISSON S.; GROSSMAN, J.D. Anatomy of the domestic animals. PHILADELPHIA, W.B. Saunders. 1938.

STOBO, J.H.B. et. al. Rumen development in calf 1- The effect of diet containing different proportions of concentrates to hay on rumen development. British J. Nutr., v.20, p.171-91, 1966.

STROBEL, H.J. ; RUSSEL, J.B. Effect of $\mathrm{pH}$ and energy spilling on bacterial protein synthesis by carbohydrate-limited cultures of mixed rumen bacteria. J. Dairy Scy., v.69, p.2941-47, 1986.

STROZINSKI, L.L.; CHANDLER, P.T. Effects of dietary fiber and aciddetergent lignin on body fill of ruminanting calves. J. Dairy Sci., v.54, p.1491-5, 1971.

SWANSON, E.W.; HARRIS JUNIOR, J.D. Development of rumination in the young calf. J. Dairy Sci., v.41, n.12, p.1768-76, 1958

THOMAS, D.B.; HINKS, C.E. The effect of changing in the physical form of roughage on the performance of the early weaned calf. Anim. Prod., v.35, p.375-84, 1982.

THOMAS, D.B.; HINKS, C.E. A note on the optimum level of routhage inclusions in the diet of the early weaned calf. Animal Prod., v.36, p.299, 1983 
TRAUB, O.A.; KESLER, E.M. Effect of dietary protein - energy ratios on digestion and growth of Holstein calves at ages 8 to 18 weeks, and on free amino-acids in blood. J. Dairy Sci., v.55, n.3, p.348-52, 1972.

UGARTE, J. et. al. Effects of suckling once on twice daily on milk production and calf growth. Rev. Cubana de Ci. Agric., v.6, p.173, 1972.

VALVASORI, E. et. al. Estabelecimento de protozoários ciliados no rúmen de bezerros alimentados com proteína de diferentes formas de soja. B. Ind. Anim., Nova Odessa, SP, v.49, n.2, p.113-7, 1992.

VAN SOEST, P.J. Nutritional ecology of the ruminant: ruminant metabolism. Nutritional studies. The cellulolytic fermentation and the chemistry of forages and plant fibers. Corvallis, OR. O \& B Books, 1982. Cap. 7, p.95-117: Carbohydrates.

WARNER, R.G. et. al. Dietary factors influencing the development of the ruminant stomach. J. of Agric. and Food Chem., n.9, p.788-92, 1956.

WESTON, R.H. et. al. Factors limiting the intyake of feed by sheep. XIV Comparision of voluntary feed consuption and various transactions in the alimentary tract between lambs and sheep fed roughage diets. Australian Journal of Agricultural Research, 1989, 40, p.625-42 apud MURPHY, M.R.; KENNEDY, P.M. Particle Dinamics, In: Forbes. J.M.; France, J. Quantitative Aspects of Ruminant Digestion and Metabolism, Cambridge, CABI. 1993, cap.4, p.87-106.

WILLIAMS, P.E. et. al. The effects on growth, food intake and rumen volume of including untreated or ammonia-treated barley straw in a complete diet for weaning calves. Anim. Prod., v.41, p.63-74, 1985. 
YODER, R.D. et. al. Influence of rumen protozoa and bacteria upon cellulose digestion in vitro. J. Anim. Sci., v.25, p.609-12, 1966. 